\title{
Voice and Relativization without Movement in Malagasy
}

abstract Like many W. Austronesian languages Malagasy (Madagascar) is verb initial with a rich voice system on which most major syntactic processes in the language depend $^{1}$. Here we derive and compositionally interpret nuclear Ss in different voices. Their "theta equivalence", similar to English actives and passives, is a corollary. No A or A' movement is used. We illustrate one major syntactic process, relativization, that builds on the voice system, and we derive the "subjects only" constraint in a new way. Again, no (operator) movement is used. We treat voice morphologies as structure building operations as in K\&S (Keenan \& Stabler 2003). They are special cases of Merge. We introduce one novel notion, language invariant, to illustrate structural constraints over non-isomorphic expressions.

This paper is organized as follows: 1. presents a sample of the voice phenomena we analyze. 2. reviews the two mainstream approaches to these phenomena. 3. presents our own analysis. 4. derives and interprets relative clauses and 5. concludes.

\section{Voice and Nuclear Clause Structure in Malagasy}

Malagasy verbs are built by successive affixation of roots (which may or may not be words). For example from the root $^{2}$ tolotra 'offer' we construct among others the four verbs in (1). The translation of (1a) suffices for each. Exceptionally we mark stress, to show that it is preserved under prefixing but shifts right under suffixing.

(1) a. [P1 $\varnothing+$ man+tólotra (manólotra) vary ny vahiny amin'ny lovia vaovao] aho pres+man+offer rice the guests on'the dishes new 1 s. $\delta$ I offer rice to the guests on the new dishes

b. [P1 $\varnothing+a+$ tólotra+ko (atólotro) ny vahiny amin'ny lovia vaovao] ny vary pres+a+offer+1s.poss the guests on'the dishes new the rice

$$
\begin{aligned}
& \text { c. [ }{ }_{\mathrm{P} 1} \varnothing+\text { tólotra+na+ko (tolórako) vary amin'ny lovia vaovao] ny vahiny } \\
& \text { pres }+ \text { offer }+ \text { ina }+1 \text { s.poss rice on'the dishes new the guests } \\
& \text { d. [P1 } \varnothing+\text { man+tólotra+ana+ko (anolórako) vary ny vahiny] ny lovia vaovao } \\
& \text { pres }+[[\text { man }+ \text { offer }]+\text { ana }]+1 \text { s.poss rice the guests the dishes new }
\end{aligned}
$$

The primary constituent division, bracketed, receives extensive support and is agreed upon by all generative grammarians (Keenan 1976, 1995; GHT 1992; Paul 1999; R\&T 2000; Sabel 2003; Pearson 2005). We differ on the category and internal structure of the bracketed constituent, which theory neutrally we call a $\mathrm{P} 1$, one place predicate phrase. Tests for this constituency are: (1) the yes-no question particle ve is placed at its right

Abbreviations: $1=1^{\text {st }}$ person, $3=3^{\text {rd }}$ person, $\mathrm{s}=$ singular; $\mathrm{pl}=$ plural, $\mathrm{AG}=$ Agent, $\mathrm{TH}=$ Theme, GL = Goal, dem = demonstrative, poss = possessor; acc $=$ accusative, Rec = reciprocal, Cause $=$ Causative, pres $=$ present; $p s t=$ past, Foc $=$ focus, excl $=$ exclusive . 
edge in all the Ss in (1). Placement elsewhere is ungrammatical (Pearson 2005). (2) the DP following the P1 has the same default case $(\delta)$ in all the Ss in (1). (3) the P1 is meaningful - it denotes a property of individuals and occurs as a constituent with that meaning in many other constructions, such as relative clauses. Voice morphology in (1) has not been glossed, so as not to decide its morphosyntactic role before analysis. We treat tense morphology as merging outside voice morphology and largely ignore it.

\subsection{Morphosyntactic background of the verbs in (1)}

[1] Affixal complexity. Each verb in (1a,b,c) is a direct affixation of the root tolotra. Affixes with roots in their domains are called primary. The verb in (1d) is built by suffixing -ana to the already prefixed verb in (1a) less the initial $m$ (see [4] below). -ana is a non-primary affix and (1d) has two applications of Merge. -ana suffixes verbs with some 6 other prefixes, so $(m) a n-+-a n a$ is not a fixed circumfix.

The complexity of -ana is dramatically reflected in child language acquisition. HNM (Hyams, Ntelitheos, Manorohanta 2006), an empirical longitudinal study of three Malagasy children, finds that -ana forms are learned well after the man- and -ina forms (the $a$ - prefix is even rarer, both in HNM and in adult speech, K\&M 2001).

[2] Affixal selection. The affixes in (1a,b,c) select their roots. Treating them as verb building functions, listing the roots they select just means defining their domain. In contrast the -ana suffix in (1d) selects the verbs it combines with according to the affix used to build the verb. It is $100 \%$ productive, combining with all $(\mathrm{m})$ an- prefixed verbs, no roots, $a$ - prefixed verbs or -ina suffixed ones.

[3] Imperatives (Koopman 2005). All the verbs v in (1) have an imperative form, $\operatorname{imp}(v)$, in (2). imp suffixes man verbs with $a$, and a, ina and ana verbs as in (1b,c,d) with $o(=/ \mathrm{u} /)$, which dissimilates to $y(=/ \mathrm{i} /)$ if the root contains a stressed $o$. Suffixing weak expressions - ones with antepenultimate stress ending in -na, -ka, or -tra, like

tólotra, triggers partial loss of the ending. ( $t r=/ t^{r} /$ is a voiceless post-alveolar affricate). So the imp function groups the verbs in $(1 b, c, d)$ together and excludes that in (1a).

(2) a. manolóra (man+tólotra+a) vary azy offer man+offer+imp rice them

Offer them rice

b. atolóry (a+tólotra+y) azy ny vary offer a+offer+imp them the rice Offer them the rice

c. tolóry (tólotra+y) vary izy offer offer+imp rice they

(the -ina form) Offer them rice 
d. anolóry ([man+tolotra]+y) vary azy ny lovia vaovao offer man+offer+imp rice them the dishes new

(the -ana form)

Use the new dishes to offer them rice

[4] Present tense marking is uniformly zero in (1). Future and past replace $\varnothing$ by $h-/ n$ - (ho/no before consonants) but we also lose the initial $m$ in (1a): hanolotra 'will offer', nanolotra 'offered'. Yet treating $m$ as a present tense marker is inaccurate (Builles 1984; Pearson 2005) as it also occurs in the, tenseless, imperative. An additional half dozen verbal prefixes use this $m$, and some 20 verbs (3.4.1) are formed by directly prefixing $m$ to roots. Traditional grammars - [RR 1971], Rahajarizafy 1960 and Malzac 1926, treat $m$ as an integral part of $m$ initial prefixes.

[5] Agent marking groups (1b,c,d) together excluding (1a). In (1a) the semantic Agent of the verb is aho, the DP sister to the P1. Linguists often accord a special, and pretheoretically unclear, status to the DP sister of the P1, using terms such as "subject", "topic", "pivot", or "trigger". We just call it the DP sister of the P1, limiting ourselves to what we can structurally identify. In (1b,c,d) the Agent is expressed by a "possessive" suffix -ko on the verb. Malagasy has three pairwise disjoint case series of pronouns:

(3)

$\begin{array}{clll}\text { Singular Pronouns } & \delta & \text { acc } & \text { poss } \\ \text { I } & \text { aho } & \text { ahy } & -k o \\ \text { You } & \text { ianao } & \text { anao } & -n a o \\ \text { He, she, it } & \text { izy } & \text { azy } & -n y .\end{array}$

The poss pronouns, by definition, express possession in nominals, like my mother. Like their full DP counterparts, they are morphologically bound, partially illustrated below. In (4a',b',c') atao is an a- prefix verb, like atolotra in (1b), built from the root tao(v) 'do'.
(4) a. trano
b. ny tranoko
c. ny tranon-dRabe ${ }^{4}$
the house+my
the house+of+Rabe
a'. atao
$\mathbf{a}+$ do
b'. ataoko
$\mathbf{a}+$ do +1 s.poss
c'. ataon-dRabe
a+do+Rabe.poss

The possessive construction is morphophonemically complex (See Paul 1996, K\&P and Ntelitheos 2005). The forms in (4c,c') involve a nasal "linker" and if the host is weak ([3] above) its ending drops, but the non-continuant feature of its consonant is inherited by the possessor, triggering the mutation of an initial continuant to the closest noncontinuant. There are 7 such mutations: $\mathrm{h} \rightarrow \mathrm{k}, \mathrm{l} \rightarrow \mathrm{d}, \mathrm{r} \rightarrow \mathrm{d}^{\mathrm{r}}$ (a post alveolar affricate), etc. (5c,c') lack the nasal linker in (4c,c').
(5) a. tongotra
foot
a'.atolotra
b. ny tongotro
the foot+my 'my foot'
'offers'
b'.atolotro
offer+my 'I offer'
c. ny tongo-dRabe
the foot-Rabe 'Rabe's foot'
c'atolo-dRabe offer+Rabe 'Rabe offers'


In addition to nominal possessors poss pronouns in Malagasy express Agent phrases of many verbs and most objects of prepositions.

The $\delta$ pronouns are used for DP sisters of P1s. They are also default forms in two cases (Pearson 2005). The first is with coordinate possessors:

(6) a. ny tranon-dRabe sy Rasoa the house-Rabe.poss and Rasoa Rabe and Rasoa's house b. ny tranon-dRabe sy izy (*-ny) the house-Rabe.poss and $3 . \delta$ (*-3.poss) "Rabe's and her house"

Secondly, Malagasy augments $3^{\text {rd }}$ person pronouns in the $\delta$ or acc series with plural demonstratives, like ireo 'those', or kin terms, like mivady 'spouses'or mirahalahy 'brothers'. Bare third person pronouns (all three series) can be singular or plural but the poss form -ny, always unstressed, cannot host these augments. So we commonly find:

(7) a. ny tranon'izy mivady the house'3.ठ spouses The spouses house b. ny tanan'izy mirahalahy the village' $3 . \delta$ brothers The brothers' village

Two prepositions, noho 'against, than' and afa-tsy 'except' take their complements in the $\delta$ series. (Rabe in (8), as DP sister to the P1, can itself be replaced with izy).

(8) [Lehibe noho izy] Rabe Rabe is bigger than him

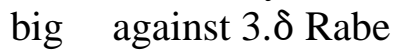

We do not read $\delta$ as "nominative" as that suggests that the DP sister to P1 has the properties of subjects in better known languages. But the split in subject properties between two structurally distinct DPs that Schachter 1976 demonstrated for Tagalog mostly carries over to Malagasy. So we will not bias our discussion with a terminology that favors one of the possible analyses.

Lastly, the acc pronouns are, by definition here, used for non-poss sisters of transitive verbs, usually interpreted as Theme or Goal. A few adjectives, such as antonina 'suitable' and feno 'full' and a few prepositions, such as lavitra 'far (from)' and tahaka 'like' take acc complements. acc forms also express predicate possessives, as in Ahy io 'lit: me that' = That is mine.

\section{Mainstream approaches to nuclear clause structure in Malagasy}

There are two mainstream approaches to nuclear clause structure in Malagasy, both clearly summarized in HNM. The first, GHT 1992, developed in Paul 1999, integrates Schachter's "two subjects" into mainstream theory. The structure they propose for a transitive S is an IP with an empty Specifier. The complement of the head of IP is a VP whose Spec is assigned the Actor theta role. The complement of the head V is assigned Theme. Verbal morphology is basic: man assigns case to the Theme, whence the otherwise caseless Actor raises to Spec,IP to check case. ina assigns case to the Actor, 
so the Theme raises to Spec,IP. The two subjects are the DPs in Spec,IP and Spec,VP, which share subject properties. Paul 1999 treats the $a$ prefix forms, as in (1b).

The determining difference between their approach and ours in 3. is that on theirs, theta roles are assigned in pre-movement structure to unique positions (a nearly constant property of passives from Chomsky 1957 through Mahajan 1994 to Collins 2005). So a DP is assigned the Agent theta role in Spec,VP and only there, regardless of whether it later raises to Spec,IP. Similarly DPs are only assigned Theme as complements of V. So DPs with the same theta role in Ss like (1a - d) receive it in the same pre-movement position. In contrast, on our approach Agents (and Themes) originate in the positions in which they audibly occur. No movement is needed, or used.

The second mainstream approach was pioneered in Richards 2000 for Tagalog and developed for Malagasy in Pearson 2005. They propose that the DP sister to P1 behaves like a topic in V2 languages such as Icelandic. Pearson treats a clause as a TopP (Topic Phrase) whose Spec is initially filled with a DP. The complement of the head of TopP is whP whose Spec is initially empty. The complement of its head is TP (Tense Phrase) and the complement of its head is the VP which includes all the arguments of the verb, one of which must be an empty operator. Theta roles and case are assigned in situ. The empty operator moves to Spec,whP where it is coindexed with the DP in Spec,TopP which inherits its case and theta role. Voice morphology, man and ina, is realized on the verb according to the position from which the empty operator was moved. So movement determines morphology, rather than morphology determining what can move. As in GHT/Paul, theta roles are assigned in fixed positions in the pre-movement structure. A DP interpreted as Agent is either in Spec, VP or is coindexed with an empty operator that originated there. Analogously for DP Themes.

\section{A proposal for the core voice system in Malagasy}

We treat a language as a set of categorized expressions $(\mathrm{s}, \mathrm{C})-\mathrm{s}$ a phonological string, $\mathrm{C}$ a category name - derivable from lexical (underived) expressions by structure building functions. The lexical expressions of Malagasy are listed in Abinal \& Malzac 1963 and Rabenilaina 1993. The primary structure building function is Merge, particular cases of which is the merging of about 20 voice affixes, which, to be succinct, we treat as predicate building functions (PBFs) ${ }^{3}$. They form tenseless Pn's, $n$-place predicate phrases, by affixation. The core grammar of Malagasy is given by these affixes plus the language general Predicate-Argument and Modifier-Head cases of Merge. 3.1 presents enough Malagasy PBFs to show that they are not just an active/passive alternation. We also show how theta roles and theta equivalence derive from semantic interpretation. We start with P2s in the present tense. 3.2 presents general constraints on PBFs.

3.1.1 man is a PBF illustrated in (9) ${ }^{4}$. Its domain is a listed set of roots.

(9) man+enjika (manenjika) ny jiolahy Rabe

man+chase the thief Rabe

Rabe chases/is chasing the thief 
enjika is a root of category $\mathrm{RT}_{\{\mathrm{AG}, \mathrm{TH}\}}$. man maps (enjika, $\mathrm{RT}_{\{\mathrm{AG}, \mathrm{TH}\}}$ ) to the $\mathrm{P} 2$ manenjika of category S[DP $\left.{ }_{\text {acc:TH}}, \mathrm{DP}_{\delta: \mathrm{AG}}\right]$, which selects a $\mathrm{DP}_{\text {acc }}$ interpreted as Theme to form a P1, manenjika ny jiolahy, of category $\mathrm{S}\left[\mathrm{DP}_{\delta: A G}\right]$, which merges with a $\mathrm{DP}_{\delta}$ interpreted as Agent to form a P0 ( $0=$ no features left to check). The action of man is illustrated in (10a) and the derivation of (9) in (10b).

(10)a. $\quad\left(\right.$ enjika, $\left.\mathrm{RT}_{\{\mathrm{AG}, \mathrm{TH}\}}\right) \quad \rightarrow \quad$ (manenjika, $\left.\mathrm{S}\left[\mathrm{DP}{ }_{\text {acc:TH}}, \mathrm{DP}_{\delta: \mathrm{AG}}\right]\right)$

b.

\begin{tabular}{ccc}
\multicolumn{4}{c}{$\mathrm{S}\left[\mathrm{DP}_{\delta: \mathrm{AG}}\right]$} & \\
$\mathrm{S}\left[\mathrm{DP}_{\mathrm{acc:TH}}, \mathrm{DP}_{\delta: \mathrm{AG}}\right]$ & $\mathrm{DP}_{\mathrm{acc}}$ & $\mathrm{DP}_{\delta}$ \\
& $\mathrm{RT}_{\{\mathrm{AG}, \mathrm{TH}\}}$ & \\
$\operatorname{man}{ }^{\text {enjika }}$ & ny jiolahy & Rabe
\end{tabular}

3.1.1.1 Syntax Merge concatenates a string s of category $\mathrm{S}\left[\mathrm{C} 1_{\mathrm{c} 1: \theta 1}, \ldots, \mathrm{Cn} \mathrm{n}_{\mathrm{cn}:(\theta \mathrm{n})}\right]$ with a t of category $\mathrm{C} 1_{\mathrm{c} 1}$, satisfying a category (C1) and a case (c1) requirement, to form $\left.\mathrm{s}\right\urcorner \mathrm{t}$ of category S[C2 $\left.2_{\mathrm{c} 2: \theta 2}, \ldots, \mathrm{Cn}_{\mathrm{cn}:(\theta n)}\right]$. Pictorially in (11b):

(11) a.

Merge

$\left.\left(\mathrm{s}, \mathrm{S}\left[\mathrm{C} 1_{\mathrm{c} 1: \theta 1}, \ldots, \mathrm{Cn} \mathrm{cn}_{(\theta \mathrm{n})}\right]\right),\left(\mathrm{t}, \mathrm{C} 1_{\mathrm{c} 1}\right) \quad \Rightarrow \quad(\mathrm{s}\urcorner \mathrm{t}, \mathrm{S}\left[\mathrm{C} 2_{\mathrm{c} 2: \theta 2}, \ldots, \mathrm{Cn} \mathrm{cn}_{\mathrm{c}(\theta \mathrm{n})}\right]\right)$

b.

$$
\begin{aligned}
& \left(\mathrm{s}^{\frown} \mathrm{t}, \mathrm{S}\left[\mathrm{C} 2_{\mathrm{c} 2: \theta 2}, \ldots, \mathrm{Cn}_{\mathrm{cn}:(\theta \mathrm{n})}\right]\right) \\
& \text { Merge } \\
& \text { (s, S[C1 } \left.\left.1_{\mathrm{c} 1: \theta 1}, \ldots, \mathrm{Cn}_{\mathrm{cn}:(\theta \mathrm{n})}\right]\right), \quad\left(\mathrm{t}, \mathrm{C} 1_{\mathrm{c1}}\right)
\end{aligned}
$$

So Dom(Merge), the domain of Merge, contains pairs $<\mathrm{u}, \mathrm{v}>$ of expressions in which the category and case of $\mathrm{v}$ satisfy (are checked against) the category and case required by $\mathrm{u}$. Theta role $\theta \mathrm{i}$ will be assigned to the $\mathrm{i}^{\text {th }}$ argument, see 3.1.1.2. $\theta \mathrm{n}$, but no other $\theta \mathrm{i}$, is absent in one case (see 3.4.5)). A P0 derived by successive applications of PBFs has all arguments assigned case and all but possibly the last interpreted with a theta role.

3.1.1.2 Semantics For each domain $\mathrm{E}$, (enjika, $\left.\mathrm{RT}_{\{\mathrm{AG}, \mathrm{TH}\}}\right)$ denotes a set of pairs of elements of E. A P1 denotes a property, a function from E into \{True, False $\}^{5}$. And in general a Pn+1 maps entities to Pn denotations. To simplify we use DPs interpretable as elements of E. Extending them to generalized quantifiers is standard (Keenan 1996).

Theta roles are relations between entities in $\mathrm{E}$ and $\mathrm{n}$-ary predicate denotations, $\mathrm{n}>0$. We write $\llbracket \mathrm{d} \rrbracket$ for the semantic interpretation of an expression $d$, and we simplify notation by omitting the category coordinate of an expression when clear from context. Here and later $\in$ is the set membership relation, $\wedge$ is and, and iff is if and only if. Then, 


$$
(\mathrm{x}, \mathrm{y}) \in \llbracket \text { enjika } ₫ \wedge \text { Theme }(\mathrm{y} \llbracket \text { enjika }) \rrbracket) \wedge \operatorname{Agent}(\mathrm{x}, \llbracket \text { enjika } \rrbracket) .
$$

We mostly wrote enjika instead of <enjika, $\mathrm{RT}_{\{\mathrm{AG}, \mathrm{TH}\}}>$ above. Some may want to read

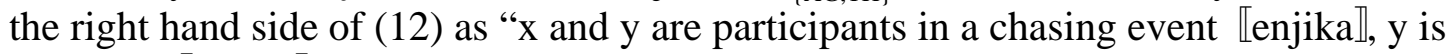

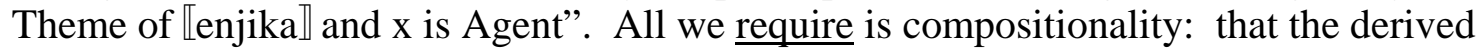
expression man(enjika) be interpreted as a function of what it is derived from, enjika.

From (12) it is the P2 man(enjika), not just the root enjika or the prefix man-, which matches arguments and theta roles. (9) is True (in E) iff the pair <the thief, Rabe $>$ is in

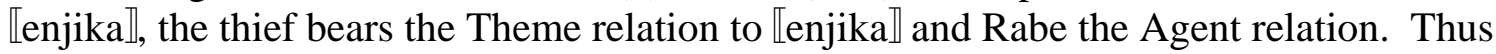
theta role assignment derives from semantic interpretation.

3.1.2 mi is a PBF whose domain is a listed set of roots. It prefixes them with mi- fully preserving the root, unlike man. It is the most frequent voice affix (K\&M 2001) and the most productive. Hilda Koopman (p.c.) notes nonce uses like miparticiper 'participates' on the web. mi builds many $\mathrm{P} 1 \mathrm{~s}$ from roots of category $\mathrm{RT}_{\{\mathrm{AG}\}}$ : miasa 'works', miteny 'speaks', mihomehy 'laughs', milomano 'swims', mitomany 'cries', miezaka 'strive'. It also builds some P1s with Theme arguments: miely 'be dispersed', mianjera 'collapse', mifaly 'to be happy, rejoice', migadra 'to be in chains, prison.

mi is sometimes called an intransitive verb former, but that is a distortion. It applies to very many roots of category $\mathrm{RT}_{\{\mathrm{AG}, \mathrm{TH}\}}$ building $\mathrm{P} 2 \mathrm{~s}$ of category $\mathrm{S}\left[\mathrm{DP}{ }_{\mathrm{acc}: \mathrm{TH}}, \mathrm{DP}_{\delta: \mathrm{AG}}\right]$, like man. Here are 15 examples, another 15 are easily found: mikapoka 'beats', mividy 'buys', mivarotra 'sells', mitady 'seeks', mifidy 'chooses', mikarakara 'takes care of', mitaona 'transports', mijery 'watches', miantso 'calls', mibaby 'carries', mitana 'holds', mitazana 'espies', mitily 'spies on', miteraka 'give birth to', mitelina 'swallow', misambotra 'capture'. None of these roots are also in the domain of man. Thus if we know of a Pn that it interprets its $\mathrm{DP}_{\delta}$ as Agent we cannot predict the verbal prefix: it is man- with enjika 'chase' and many others, but mi- with kapoka 'beat' and many others. mi also prefixes many roots that are in the domain of man. Rahajarizafy 1960:50 notes:

(13) When mi and man apply to the same root $r$ the mi verb usually has lesser valence.

Rahajarizafy 1960 notes a few cases where mi(r) and man(r) have the same valency, and two where mi(r) has greater valency. But (13) is far and away the norm, so it can help language learners. The precise relations between $\mathbf{m i}(\mathrm{r})$ and $\mathbf{m a n}(\mathrm{r})$ require a large scale study. Most comonly man(r) is a rough semantic causative of mi(r): mihidy 'is locked' / manidy 'locks (tr); milatsaka 'falls' / mandatsaka 'drops', milahatra 'line up (intr)' / mandahatra 'arrange in lines'; miverina 'come back' / mamerina 'give back'; mivory 'gather (intr) / mamory 'gather (tr)'. But in several cases the two verb forms have sufficiently diverged in sense that we lose any compositional relation between them: mianatra 'studies' / mananatra 'admonishes'; mipetraka 'sits, resides'/ mametraka 'puts'; milaza 'says' / mandaza 'praises, celebrates'. 
3.1.3 ina is a PBF whose domain includes both roots and mamp- prefixed verbs (such verbs are causatives) ${ }^{6}$. ina suffixes -ina (-ena, $\left.-(a) n a\right)$ preserving root final consonants ${ }^{7}$. A p in Dom(ina) has at least two theta roles to assign. (14) exhibits the action of ina on the root enjika. We mark stress to remind the reader that suffixing triggers stress shift. (15b) summarizes our derivation of (15a), and (16) gives its semantic interpretation.

$$
\text { ina }
$$

(15) a. enjika + ina +Rabe (enjehin-dRabe)

chase+ina+Rabe.poss

ny jiolahy

Rabe chases the thief

the thief

b.

\begin{tabular}{|c|c|c|}
\hline \multicolumn{2}{|c|}{$\mathrm{S}\left[\mathrm{DP}_{\hat{\delta}: \mathrm{TH}}\right]$} & \multirow[t]{2}{*}{$\mathrm{DP}_{\delta}$} \\
\hline $\mathrm{S}\left[\mathrm{DP}_{\text {poss:AG}}, \mathrm{DP}_{\delta: \mathrm{TH}}\right]$ & $\mathrm{DP}_{\text {poss }}$ & \\
\hline $\mathrm{RT}_{\{\mathrm{AG}, \mathrm{TH}\}}$ & & \\
\hline $\begin{array}{l}\text { enjika }+\quad \text { ina } \\
\text { chase }\end{array}$ & $\begin{array}{l}\text { Rabe } \\
\text { Rabe.poss }\end{array}$ & $\begin{array}{l}\text { ny jiolahy } \\
\text { the thief }\end{array}$ \\
\hline Rabe chases/is chasit & hief & \\
\hline
\end{tabular}

We gloss Rabe as Rabe.poss to indicate that Rabe combines with enjehina in the complex way that possessors combine with their heads. And enjehina interprets its $\mathrm{DP}_{\delta}$ argument as Theme (TH) and its $\mathrm{DP}_{\text {poss }}$ argument as Agent (AG). Gen 1 is the general pattern.

(16) $\llbracket$ ina(enjika) $\rrbracket(u)(v)=$ True iff $(\mathrm{u}, \mathrm{v}) \in \llbracket$ enjika $\rrbracket \wedge \mathrm{TH}(\mathrm{v}, \llbracket$ enjika $\rrbracket) \wedge \mathrm{AG}(\mathrm{u}, \llbracket$ enjika $\rrbracket)$

Gen 1 For $p$ a root with zero or more affixes, if $p \in \operatorname{Dom}(i n a)$ then

(a) ina(p) is a Pn of category $\mathrm{S}\left[\mathrm{DP}_{\text {poss: }: 11}, \ldots, \mathrm{DP}_{\delta: \theta n}\right]$, for some $\mathrm{n}>1$, and

(b) if $\mathrm{p}$ selects an Agent then $\theta 1=$ Agent

Many roots lie both in Dom(man) and Dom(ina): haja $\Rightarrow$ manaja/hajaina 'respects', vono $\Rightarrow$ mamono/vonoina 'hits, kills', la $\Rightarrow$ manda/lavina 'refuses', fonos- $\Rightarrow$ mamono/fonosina 'wraps', vaky $\Rightarrow$ mamaky/vakina 'cuts, reads'. Also many roots lie in both Dom(mi) and Dom(ina): bata $\Rightarrow$ mibata /bataina 'raises up', kapoka $\Rightarrow$ mikapoka/kapohina 'beats', antso $\Rightarrow$ miantso/antsoina 'calls'. We define:

Def 1 Nuclear Ss are theta equivalent, $\equiv_{\Theta}$, iff their arguments can be bijectively matched such that each argument in one and its match in the other have the same theta role. ('nuclear $S$ ' ${ }_{\mathrm{df}}$ P0 built just by Merging arguments with a Pn built by affixing roots).

Notice that (17a) follows immediately from (16) and (12), and in general (17b) holds 
when $\mathrm{r}$ is in the domain of both man and ina. So the derived verbs are logical converses, from which the two propositions below follow.

(17) a. $\llbracket$ man $($ enjika $) \rrbracket(y)(x)=\llbracket$ ina(enjika $) \rrbracket(x)(y)$

b. $\llbracket \operatorname{man}(\mathrm{r}) \rrbracket(\mathrm{y})(\mathrm{x})=\llbracket \operatorname{ina}(\mathrm{r}) \rrbracket(\mathrm{x})(\mathrm{y})$

Proposition 1 For $\mathrm{r}$ of category $\mathrm{RT}_{\{\mathrm{AG}, \mathrm{X}\}}$ in the domain of both man and ina,

A. nuclear Ss built from man(r) and ina(r) are theta equivalent: the $\mathrm{DP}_{\delta}$ argument of each has the same theta role as the non- $\mathrm{DP}_{\delta}$ argument of the other.

B. mi(r) and ina(r) build theta equivalent nuclear Ss when mi(r) is transitive.

Proposition 2 Nuclear Ss built from man(r) and ina(r), $r$ of category $\mathrm{RT}_{\{\mathrm{AG}, \mathrm{X}\}}$, are logically equivalent when their Agents are the same individual denoting DPs and their Themes are the same individual denoting DPs. Similarly for mi(r) and ina(r) in B.

3.1.4 The PBF a, as in (1b), prefixes $a$ - to roots, and like mi and man, applies only to roots. Gen 1 holds of $\mathbf{a}(\mathrm{p})$ just as it holds of ina(p). The $\mathrm{DP}_{\delta}$ of a P1 built by a is an "Intermediary": Theme with roots of movement or transmission, Instrument or Theme otherwise. See Paul (1999) for extensive discussion. (18b) illustrates its Theme usage.

(18) a. [man+tosika (manosika) ny fiara] Rabe

man+push the car Rabe

Rabe pushes/is pushing the car

b. [a+tosika+Rabe (atosi-dRabe)] ny fiara

a+push+Rabe.poss the car

Rabe pushes/is pushing the car

Thus we cannot predict the voice affix of a P1 which interprets its $\mathrm{DP}_{\delta}$ as Theme and its $\mathrm{DP}_{\text {poss }}$ as Agent. If the root is enjika 'chase' we use -ina, if it is tosika 'push' we use $a-$. tosika is not in Dom(ina): *tosihina. Similarly tao $(v) \Rightarrow$ manao/atao 'do, make' and verina $\Rightarrow$ mamerina averina 'return (sth)' accept man- and $a$ - but not -ina. voaka 'exit' derives mivoaka 'go out' and mamoaka/avoaka 'expell' but *voahina; lahatra $\Rightarrow$ mandahatra and alahatra 'put in a line' but *laharina, and tono $\Rightarrow$ mitono and atono 'grills' but *tonoina. There are many more roots in Dom(ina) not in Dom(a): lalao 'play' $\Rightarrow$ lalaovina but *alalao; la 'refuse' $\Rightarrow$ lavina but *ala; haja 'respect' $\Rightarrow$ hajaina but *ahaja. But usually both a and ina apply to ditransitive roots of transmission, as in (1). a assigns Theme to its $\mathrm{DP}_{\delta}$ and ina assigns Goal. Similar roots are roso $\Rightarrow$ aroso/ rosoana 'serve' and solo $\Rightarrow$ asolo/soloana 'replace, substitute'. This paradigm is not limited to verbs of transmission:

(19) a. man+tondro (manondro) ny tranony amin'ny tehiny Rabe man+point-out the house-his with'the cane-his Rabe Rabe points out his house with his cane 
b. a+tondro+Rabe (atondron-dRabe) ny tranony ny tehiny a+point-out Rabe.poss the house-his the cane-his

c. tondro+ina+Rabe (tondroin-dRabe) amin'ny tehiny ny tranony point-out+ina+Rabe.poss with'the cane-his the house-his

Here are the values of man, a, and ina at ditransitive roots $r$ of category $\mathrm{RT}_{\{\mathrm{AG}, \mathrm{GL}, \mathrm{TH}\}}$. (20a) says that the P3 man(r) interprets its z argument as Theme, the resulting function interprets its y argument as Goal, and the final P1 function interprets its $\mathrm{x}$ argument as Agent. In contrast the a verb in (20b) interprets its first argument as Agent, its second as Goal and its last as Theme. And the ina verb in (20c) interprets its first argument as Agent, its second as Theme, and its last as Goal. $\mathrm{R}$ is the ternary relation denoted by $\mathrm{r}$.

(20) a. $\llbracket \operatorname{man}\left(r, R_{\{A G, T H, G L}\right) \rrbracket(z)(y)(x)=$ True iff

$$
<\mathrm{z}, \mathrm{y}, \mathrm{x}>\in \mathrm{R} \wedge \mathrm{THEME}(\mathrm{z}, \mathrm{R}) \wedge \operatorname{GOAL}(\mathrm{y}, \mathrm{R}) \wedge \operatorname{AGENT}(\mathrm{x}, \mathrm{R})
$$

b. $\llbracket \mathbf{a}\left(\mathrm{r}, \mathrm{RT}_{\{\mathrm{AG}, \mathrm{TH}, \mathrm{GL}\}}\right) \rrbracket(\mathrm{x})(\mathrm{y})(\mathrm{z})=$ True iff

$$
<\mathrm{z}, \mathrm{y}, \mathrm{x}>\in \mathrm{R} \wedge \operatorname{AGENT}(\mathrm{x}, \mathrm{R}) \wedge \operatorname{GOAL}(\mathrm{y}, \mathrm{R}) \wedge \operatorname{THEME}(\mathrm{z}, \mathrm{R})
$$

c. $\llbracket$ ina $\left(r, R T_{\{A G, T H, G L}\right) \rrbracket(x)(z)(y)=$ True iff

$$
<\mathrm{z}, \mathrm{y}, \mathrm{x}>\in \mathrm{R} \wedge \operatorname{AGENT}(\mathrm{x}, \mathrm{R}) \wedge \operatorname{THEME}(\mathrm{z}, \mathrm{R}) \wedge \operatorname{GOAL}(\mathrm{y}, \mathrm{R})
$$

(20b,c) are theta equivalent, as are (1b,c). So theta equivalence doesn't just apply to pairs we might analogize to active vs passive in English. And we now extend Proposition 1:

C. For a two theta role root $r$ in the domain of both man and a, nuclear Ss built from man(r) and $\mathbf{a}(\mathrm{r})$ are theta equivalent, the $\mathrm{DP}_{\delta}$ argument of one bearing the same theta role as that of the non-DP ${ }_{\delta}$ argument of the other.

D. For $r$ a ditransitive root of transmission in the domains of man, a, and ina, the three nuclear Ss they build from $r$ are theta equivalent, as in (20) above.

3.1.5 Interim summary We have exhibited several structure building affixes which derive theta equivalent P0s (Ss). None uses Move. And we have seen how an explicit semantics can guarantee theta equivalence when DPs with the same theta role originate in structurally different positions. This is a usual semantical pattern: $(21 \mathrm{a}, \mathrm{b})$ for example are syntactically non-isomorphic but logically equivalent, which follows from their
a. $(\mathrm{P} \& \mathrm{Q})$
b. $\quad \neg(\neg \mathrm{P}$ or $\neg \mathrm{Q})$

compositional interpretation - specifically the meanings of and, or, and not ( $\neg)$. And what we have done above is show that structurally non-isomorphic nuclear Ss are semantically equivalent in a certain respect - namely, they are theta equivalent. 


\subsection{General Constraints on Case and Theta Role Assignment}

We consider further PBFs below, but the four we have presented - man, mi, ina, and a already illustrate some general properties of case and theta role assignment that Malagasy satisfies. We call them axioms as they are true of Malagasy, don't follow from other assumptions, and they constrain our further analysis. As indicated, some apply to languages other than Malagasy. We use $F$ to range over affixal PBFs, $r$ over roots, $p$ over roots with zero or more affixes; $\Theta(p)$ is the set of theta roles associated with $\mathrm{p}^{8}$.

Axiom 1 limits to $\Theta(r)$ the theta roles a predicate $F(r)$ built from $r$ can assign. And all arguments must be assigned a theta role, but not all elements of $\Theta(\mathrm{r})$ need be assigned, as in milatsaka 'fall' vs mandatsaka 'drop'. Axiom 1 applies to languages which affix roots to form Pn’s (Semitic and Bantu come to mind).

Axiom 1 For all $\mathrm{F}(\mathrm{r})$ of category $\mathrm{S}\left[\mathrm{C} 1_{\mathrm{c} 1: \theta 1}, \ldots, \mathrm{Cn}_{\mathrm{cn}: \theta \mathrm{n}}\right], \theta 1, \ldots, \theta \mathrm{n} \in \Theta(\mathrm{r})$

Axiom 2 For all $\mathrm{F}(\mathrm{p})$ of category $\mathrm{S}\left[\mathrm{C} 1_{\mathrm{c} 1: \theta 1}, \ldots, \mathrm{Cn}_{\mathrm{cn}:(\theta \mathrm{n})}\right]$,
a. $\quad \theta \mathrm{i} \neq \theta \mathrm{j}, \quad$ all $1 \leq \mathrm{i} \neq \mathrm{j} \leq \mathrm{n}$
and
b. $\quad \theta j$ is absent iff $\mathrm{j}=\mathrm{n}$ and $\mathrm{F}=$ ana , all $1 \leq \mathrm{j} \leq \mathrm{n}$

So Pns derived by PBFs never assign the same theta role to distinct arguments. Only the last argument may lack a theta role, and that iff $\mathrm{F}=$ ana (below). If $\mathrm{F} \neq$ ana then axiom $2+$ Merge guarantees a bijective relation between argument expressions of affixal Pns and their assigned theta roles, so in this weak sense the Theta Criterion holds for all but one affix. But note that nothing blocks a given real world object from being both Agent and Theme of a given predicate, as in Namono tena Rabe 'Rabe killed himself'.

Axiom 3 For all s of category $\mathrm{S}\left[\mathrm{C} 1_{\mathrm{c} 1: \theta 1}, \ldots, \mathrm{Cn}_{\mathrm{cn}:(\theta \mathrm{n})}\right]$,
a. $c j=\operatorname{poss} \Rightarrow \mathrm{j}=1$
all $1 \leq \mathrm{j} \leq \mathrm{n}$
$(\Rightarrow=$ “implies”, here and later)
b. $c j=\delta$ iff $j=n$
all $1 \leq \mathrm{j} \leq \mathrm{n}$

So from (3a) if a Pn selects a $\mathrm{DP}_{\text {poss }}$ then that is its first argument. So a Pn can have at most one $\mathrm{DP}_{\text {poss }}$ argument. (3b) says that the last argument of a Pn is in the default case $\delta$. No other argument is assigned $\delta$ case and Malagasy lacks quirky case. This is as close as we get to the EPP. Axiom 3 requires a $\mathrm{Pn}$ to have exactly one $\mathrm{DP}_{\delta}$ and not more than one $\mathrm{DP}_{\text {poss. }}$. But they may have more than one $\mathrm{DP}_{\text {acc }}$. man(ome) $=$ manome 'gives' has two, as do causatives of P2s, not discussed here.

Malagasy verbs are divided into two major syntactic classes according as they select a $\mathrm{DP}_{\text {poss }}$ or not. Axiom 4 says that this is decided entirely by the choice of voice affix:

Axiom 4 For all $F$, either for all $\mathrm{p} \in \operatorname{Dom}(\mathrm{F}), \mathrm{F}(\mathrm{p})$ selects a $\mathrm{DP}_{\text {poss }}$ or for all $\mathrm{p} \in \operatorname{Dom}(\mathrm{F}), \mathrm{F}(\mathrm{p})$ does not select a $\mathrm{DP}_{\text {poss }}$ 
So since man(enjika) does not select a $\mathrm{DP}_{\text {poss }}$ no other verb built by man does either. And since ina(enjika) does select a $\mathrm{DP}_{\text {poss }}$ then all other verbs built from ina do too.

Def $2 \mathrm{~F}$ is (poss) bound iff for some $\mathrm{p}, \mathrm{F}(\mathrm{p})$ selects a $\mathrm{DP} \mathrm{p}_{\text {poss }} \cdot \mathrm{F}$ is (poss) free iff for some $\mathrm{p}, \mathrm{F}(\mathrm{p})$ does not select a $\mathrm{DP}_{\text {poss }}$. The voice affix $\mathrm{F}$ introduces and the predicate it builds are also called bound (free).

By axiom 4 Def 2 is a well definition. Proposition 3 now follows from axiom 3 given that $\mathrm{DP}_{\text {poss }} \neq \mathrm{DP}_{\delta}$. Further Gen 2 holds and is massively helpful in acquisition.

Proposition 3 For all bound F, F(p) selects at least two arguments $\left(\mathrm{DP}_{\text {poss }}\right.$ and $\left.\mathrm{DP}_{\delta}\right)$.

Gen $2 \mathrm{~F}$ is free iff the affix it introduces is $m$ initial in the present tense.

Thus man and mi are free (as are ma, maha, mana, m+ø, mamp, mif, mentioned briefly later); a and ina are bound (as are voa, tafa, in mentioned briefly later).

Axiom 5 tells us how the semantic notion Agent is coded in Malagasy syntax. That is, we can identify the Agent of Pn as a function of the structure of the Pn.

Axiom 5 For $\mathrm{F}(\mathrm{p})$ of category $\mathrm{S}\left[\mathrm{DP}_{\mathrm{c1}: \theta 1}, \ldots, \mathrm{DP}_{\mathrm{cn}:(\theta \mathrm{n})}\right]$ and Agent $\in \Theta(\mathrm{p})$,
a. $\mathrm{F}$ is bound $\Rightarrow \theta 1=$ Agent and
b. $\mathrm{F}$ is free $\Rightarrow \theta \mathrm{n}=$ Agent

Axiom 5 blocks deriving an $\mathrm{F}(\mathrm{p})$ of category $\mathrm{S}\left[\mathrm{DP}_{\text {acc: AG}}, \mathrm{DP}_{\delta: \mathrm{TH}}\right]$ since $\mathrm{F}$ would be free so $\theta 2$ must be Agent, not Theme. Also blocked is an $\mathrm{F}(\mathrm{p})$ of category $\mathrm{S}\left[\mathrm{DP}_{\mathrm{poss}: \mathrm{TH}}, \mathrm{DP}_{\delta: \mathrm{AG}}\right]$ since this $\mathrm{F}$ is bound, the theta role associated with $\mathrm{DP}_{\text {poss }}$ must be Agent.

Axiom 5 is Malagasy specific, mentioning whether Pn's select a possessive DP or not. But we can generalize it in a way which helps us understand better the relation between language general properties and their realization in any given language. We first define isomorphic expressions. Let $\mathrm{G}=(\mathrm{Lex}, \mathbf{F})$ be a grammar, with Lex a lexicon, F a set of structure building functions. $\mathrm{L}(\mathrm{G})=\mathrm{L}$ the set of expressions derivable by starting with those in Lex and adding in iteratively all those obtained by applying structure building functions to ones already in the set. An automorphism $\mathrm{h}$ of $\mathrm{L}$ is a bijection from $L$ to $L$ which doesn't change how expressions are built up: if $z=F(x, y)$ iff $\mathrm{h}(\mathrm{z})=\mathrm{F}(\mathrm{h}(\mathrm{x}), \mathrm{h}(\mathrm{y}))$, any $\mathrm{F} \in \mathbf{F}$ (say $\mathrm{F}=$ Merge). So $\mathrm{z}$ and $\mathrm{h}(\mathrm{z})$ are built in exactly the same way. Expressions $\mathrm{x}, \mathrm{y}$ are isomorphic, $\mathrm{x} \simeq \mathrm{y}$, iff for some automorphism $\mathrm{h}, \mathrm{h}(\mathrm{x})=\mathrm{y}$ (in which case the automorphism h-inverse maps y to $\mathrm{x}$ ). We now generalize Axiom 5:

Axiom 5* Let $\mathrm{P}$ and $\mathrm{P}$ ' have categories $\mathrm{S}\left[\mathrm{C} 1_{\mathrm{c1}: \theta 1}, \ldots, \mathrm{Cn_{ \textrm {cn } : \theta n }}\right]$ and $\mathrm{S}\left[\mathrm{C} 1_{\mathrm{c1}: \theta 1}, \ldots, \mathrm{Cn_{ \textrm {cn } : \theta n }},\right]$ respectively. Then $\mathrm{P} \simeq \mathrm{P}^{\prime} \Rightarrow$ for all $1 \leq \mathrm{j} \leq \mathrm{n}, \theta \mathrm{j}=$ Agent iff $\theta \mathrm{j}^{\prime}=$ Agent

Axiom 5* makes it evident that man(enjika) should not be isomorphic to ina(enjika), since the former assigns Agent to $\mathrm{C} 2$, and the latter to $\mathrm{C} 1$. And indeed while they are theta equivalent, they are not isomorphic ${ }^{9}$ : If they were then the P1s they build would be, 
whence automorphisms could map $\mathrm{DP}_{\text {poss }}$ to $\mathrm{DP}_{\text {acc }}$ and conversely, an impossibility since they have different distributions. Similarly man(r) is always in Dom(ana), 3.4.5 below, and ina(r) never is, hence again neither can be mapped to the other as automorphisms preserve the domains of the structure building functions (K\&S).

Axiom 5* applies to more languages than Axiom 5 but tells us less about them. It does not entail Axiom 5, it just guarantees that the semantic notion of Agent is syntactically coded, but does not specify how. Axiom 5* does not really depend on our notation for the argument/case selection matrix. We can paraphrase it by saying that if two n-place predicates are isomorphic then for any $\mathrm{j}$, the $\mathrm{j}^{\text {th }}$ argument of one is assigned Agent iff the $\mathrm{j}^{\text {th }}$ argument of the other is. 5* holds (vacuously) if neither Pn assigns Agent, and Axiom 2a guarantees that at most one argument is assigned Agent.

The relation between Axioms 5 and 5* is of general interest. Axiom 5 does state just how Malagasy satisfies Axiom 5* for Pn's built by successive affixation of roots (as opposed to Pn's formed by coordination, or combination with adverbs for example). This pattern seems to me typical. Linguists often speak as though universal constraints appear as such as part of the grammar of each language. But more usually any given language satisfies language specific conditions which are stronger than universal ones, as is the case here. And we might generalize Axiom 5 further, to treat all theta roles alike:

Axiom 5** Let $\mathrm{P}$ and $\mathrm{P}$ ' have categories $\mathrm{S}\left[\mathrm{C} 1_{\mathrm{c} 1: \theta 1}, \ldots, \mathrm{C} \mathrm{n}_{\mathrm{cn}: \theta \mathrm{n}}\right]$ and $\mathrm{S}\left[\mathrm{C} 1_{\mathrm{c1}: \theta 1}, \ldots, \mathrm{Cn} \mathrm{n}_{\mathrm{cn}: \theta \mathrm{n}}\right]$ respectively. Then $\mathrm{P} \simeq \mathrm{P}^{\prime} \Rightarrow$ for all $1 \leq \mathrm{j} \leq \mathrm{n}, \theta \mathrm{j}=\theta \mathrm{j}^{\prime}$.

Axiom $5^{* *}$ is consistent with but weaker than current assumptions in PP/MP theories. It does not require that the relevant structures in different languages be similar. Malagasy may code theta relations in terms of verbal affixes, Korean in terms of nominal case marking, Eskimo in terms of agreement, .... All we require is that for each grammar $G$, the automorphisms of $G$ respect theta relations in the way these axioms say. We turn now to a consequence of our axioms. It uses the fundamental notion of invariant.

Def 3 A binary (n-ary) relation $R$ on a language $L$ is invariant iff $[<x, y>\in R$ iff $<\mathrm{h}(\mathrm{x}), \mathrm{h}(\mathrm{y})>\in \mathrm{R}$, all automorphisms $\mathrm{h}]$. This says that $\mathrm{h}(\mathrm{R})=\mathrm{R}$, where $\mathrm{h}(\mathrm{R})$ is $_{\mathrm{df}}$ the set of pairs $<\mathrm{h}(\mathrm{x}), \mathrm{h}(\mathrm{y})>$ for each pair $(\mathrm{x}, \mathrm{y})$ in $\mathrm{R}$. So the invariant (structural) relations among expressions of $\mathrm{L}$ are just those which are fixed (mapped to themselves) by all the automorphisms. They are what you cannot change without changing structure. As a special case a grammatical constant ("function word") is an expression that is mapped to itself by all automorphisms ${ }^{10}$. For example:

Gen 3 The Malagasy voice affixes man, mi, $a$, ina, are automorphism invariant (grammatical constants) as are ones we list later: ma, mana, mif, mamp, tafa, voa, in, and $\varnothing$ (the zero prefix). And we conjecture:

Gen 3* In any language derivational morphology is invariant. 
Note that expressions, properties (sets) of expressions, relations among expressions, etc. are invariant (structural) in exactly the same sense: fixed by the automorphisms.

Theorem 1 Theta Equivalence is Invariant. That is, for all nuclear Ss $\Phi, \Psi$

$$
\Phi \equiv_{\Theta} \Psi \Rightarrow \text { for all automorphisms } \mathrm{h}, \mathrm{h}(\Phi) \equiv_{\Theta} \mathrm{h}(\Psi)
$$

Theorem 1 says that syntactic equivalence respects theta equivalence: if $\Phi \equiv_{\Theta} \Psi$ then anything that $\Phi$ is isomorphic to is theta equivalent to anything that $\Psi$ is isomorphic to. To see what this excludes, we show that logical equivalence (having the same truth value in every model) is not invariant in English. We find $\Phi, \Psi$ with $\Phi \equiv \Psi$ but $h(\Phi) \equiv \mathrm{h}(\Psi)$ for some automorphism h. Now there is no reason to think that the numerals seven and eight are syntactically different, so let $h$ be an automorphism that interchanges them and fixes all other lexical items. (22a) and (22b) are logically equivalent but their values under h (got by swapping eight and seven) are not, so logical equivalence is not preserved under replacement by isomorphic expressions. (NOT a surprise; whether two Ss are logically equivalent depends on their meaning, not their syntactic isomorphism class).

(22) a. At least eight students came to the party

b. More than seven students came to the party

But some semantic relations are coded in the syntax. K\&S argue that the possible antecedent of an anaphor relation is of that sort: in any natural language, " $\mathrm{x}$ is a possible antecedent of an anaphor $\mathrm{y}$ in $\mathrm{z}$ " holds iff $\mathrm{h}(\mathrm{x})$ is a possible antecedent of an anaphor $\mathrm{h}(\mathrm{y})$ in $\mathrm{h}(\mathrm{z})$, all automorphisms $\mathrm{h}$. And Theorem 1 says that theta equivalence is that kind of relation. Isomorphic expressions assign theta roles comparably, as Axiom $5^{* * 11}$ says.

Further it is still true on our approach that theta roles are assigned as a function of structure. To say that the man- verb in (1a) assigns the same theta role to its $\mathrm{DP}_{\delta}$ argument as the $a$ - verb in (1b) does to its $\mathrm{DP}_{\text {poss }}$ one is like saying that $8^{2}=4^{3}$. Different functions at different arguments may have the same value. So we don't need to assume that DPs in different Ss with the same theta role originate in the same configuration.

Finally, Theorem 1 does not claim or assume that the relevant structures of one language are similar (much less isomorphic) to those of another, or even that they share grammatical categories. In contrast the claim that Agent is always and only assigned to Spec,vP does make such assumptions. In fact Theorem 1 is just a way of making explicit the idea that theta role assignment is structure dependent (Chomsky (1965:55-56; 1975:30 - 35, Radford 1997:11 - 15) - an early notion never formally defined.

3.2.1 Other Uniformity Parameters? The following candidate parameters for PBFs fail in Malagasy - though (23B) challenges Axiom $5^{* *}$ and does not fail by much.

(23) A. For $r, r^{\prime} \in \operatorname{Dom}(F), F(r)$ and $F\left(r^{\prime}\right)$ have the same number of arguments B. For $r$, $r^{\prime} \in \operatorname{Dom}(F)$, Agent $\in \Theta(r)$ iff Agent $\in \Theta\left(r^{\prime}\right)$. 
(23A) fails: man builds both P2s, like manenjika 'chases' in (10a), and also P3s, as in (1a) manolotra 'offers'. man- is the second most common voice affix (K\&M, 2001), and the majority of roots $\mathrm{r}$ in its domain have category $\mathrm{RT}_{\{\mathrm{AG}, \mathrm{TH}\}}$. man maps them to $\operatorname{man}(\mathrm{r})$ of category $\mathrm{S}\left[\mathrm{DP}_{\mathrm{acc:TH}}, \mathrm{DP}_{\delta: \mathrm{AG}}\right]$. Some present tense examples are: $\mathbf{m a n}($ didy $)=$ mandidy 'cuts', $\operatorname{man}($ vaky $)=$ mamaky 'reads', $\operatorname{man}($ vono $)=$ mamono 'kills', $\operatorname{man}($ fonos) = mamono 'envelopes'. man also applies to roots $r$ of category $\mathrm{RT}_{\{\mathrm{AG}, \mathrm{TH}, \mathrm{GL}\}}$, mapping them to man(r) of category $\mathrm{S}\left[\mathrm{DP}_{\text {acc:TH }}, \mathrm{DP}_{\text {acc:GL }} \mathrm{DP}_{\delta: \mathrm{AG}}\right]$, as in: $\boldsymbol{m a n}($ roso $)=$ mandroso 'serves', $\operatorname{man}($ tolotra $)=$ manolotra 'offers', $\operatorname{man}($ ome $)=$ manome 'gives'.

More challenging, man builds two types of intransitive verb. It applies to a few roots of category $\mathrm{RT}_{\{\mathrm{AG}\}}$ : $\operatorname{man}($ leha $)=$ mandeha 'goes', $\mathbf{m a n}($ dihy $)=$ mandihy 'dances', $\operatorname{man}($ lainga $)=$ mandainga 'lies', $\mathbf{m a n}($ lohalika $)=$ mandohalika 'kneels'. (These four examples may exhaust the agentive (unergative) intransitives man builds).

man also has some roots of category $\mathrm{RT}_{\{\mathrm{TH}\}}$ in its domain: $\operatorname{man}($ hetaheta $)=$ mangetaheta 'is thirsty', $\mathbf{m a n}($ hatsiaka $)=$ mangatsiaka 'is cold', $\operatorname{man}($ firatra +firatra $)=$ mamirapiratra 'scintillates'. These man verbs do not select an Agent, whence (23B) fails. We might analyze them as unaccusatives, but even so (23B) remains false. And the regularities that unaccusative analyses account for in Dutch, French, Italian, and Turkish do not seem to carry over to Malagasy. Malagasy has no auxiliaries of the have/be sort nor do verbs agree with arguments in $\phi$ features. There is no analogue of ne cliticization, and Malagasy seems to have no (overt or null) expletives. The closest is ny andro 'the day' in weather expressions, as in mangatsiaka ny andro 'lit: 'cold the day'. But one says in the same sense mangatsiaka aho "I am cold". And lastly, unaccusative verbs in other languages do not receive a uniform voice coding in Malagasy. Nor do weather expressions ${ }^{12}$.

Not adopting an unaccusative analysis allows the possibility that mandihy izy 'He dances' and mangatsiaka izy 'He is cold' with Agent and Theme arguments respectively are isomorphic but not theta equivalent, contra Axiom $5^{* *}$. But the two verbs classes do differ: The activity ones have standardly formed imperatives - mandéha $\Rightarrow$ mandehána 'Go!', mandíhy $\Rightarrow$ mandihíza 'Dance!', mandohálika $\Rightarrow$ mandohaléha 'Kneel!', and mandáinga $\Rightarrow$ mandaingá 'Lie!’. But the Theme argument predicates lack imperatives. Thus the former lie in Dom(imp) and the latter don’t, so they aren’t isomorphic.

Thus man intransitives illustrate an important property of automorphisms. Namely, $K \& S$, the trees representing the derivation of two expressions may be isomorphic qua ordered labeled trees, but the derived expressions may fail to be isomorphic. Reason: the tree isomorphism might map some $\mathrm{X}$ to a $\mathrm{Y}$ acceptable in that tree. But a language automorphism must map all expressions to (well-formed) expressions, and replacing $Y$ by $\mathrm{X}$ in another expression may fail to preserve grammaticality. Here is a hypothetical example. Assume that Nigel shot Trevor and Nigel shot himself have isomorphic derivations. That isomorphism maps Trevor to himself. But a language automorphism can’t do that since it would map Trevor cried to *Himself q'ed (q a P1), contradicting that automorphisms map expressions in the language to expressions in the language. 


\subsection{Predicate Building Functions and the Active - Passive Distinction}

We have illustrated two free PBFs, man and $\mathbf{m i}$, and two bound ones, ina and a. They build a significant variety of theta equivalent Ss. Many linguists (Rahajarizafy 1960, Keenan 1976, Paul 1999) have analogized from man/mi to "active" and ina/a to "passive" in English or French. In a typical man S the DP sister to the P1 is Agent, but in its theta equivalent ina $S$ it is Theme, with the Agent DP part of a constituent with the verb, as in English passives. So the DP sister of the P1 is analogized to subjects.

However as work on Malagay has deepened with contributions from many scholars over the last 15 years, the disanalogy between European passives and ina/a verbs in Malagasy has become increasingly apparent. It is well acknowledged in Pearson 2005. We review some of these differences here, as our view is one in which primary (= just one PBF affix) free and bound verbs are comparably basic (though not isomorphic).

3.3.1 Imperatives (again) If the forms in (1b,c,d) were passives it would be surprising to find them in the imperative. But we find them in abundance when a verb has both bound and free primary forms. Strikingly for example (K\&M 2004) of the 26 imperatives in the child language data of HNM, all were bound forms. Forcing a passive translation on ina verbs may lead to jarring interpretations not in fact present in the Malagasy. Compare:

(24) a. novonjen-dRabe aho

Pst.save-ina-Rabe $1 . \delta$

I was saved by Rabe

Rabe saved me b. vonjeo aho!

be+saved+imp $1 . \delta$

"Act that I may be saved!"

Save me!

The form in (24b) is the normal way to say "Save me!”. The man imperative in (25b) exists but is at best a pragmatically marked form.
(25)a. namonjy ahy Rabe pst.man+save 1s.acc Rabe Rabe saved me
b. mamonjé ahy! man+save+Imp 1s.acc Save me!

3.3.2 Position If ina/a forms are passives it is surprising, as Pearson 2005 points out, that the position of the Agent phrase is rigorously positioned relative to the verb. Usually passive Agents have the positional freedom of optional obliques.

3.3.3 Frequency K\&M's counts show that the Agent phrase in ina forms is normally present, supporting that ina verbs are better thought of as transitive (as here).

3.3.4 Control with verbs of desire and intent is vested in the Agent for both $\mathbf{m a n} / \mathbf{m i}$ verbs and ina/a verbs. Equally Agents of ina (and man) verbs can be controlled

$$
\begin{aligned}
& \text { a. } \mathrm{n}+\mathrm{i}+\mathrm{kasa} \text { hamaky }(\mathrm{h}+\mathrm{aN}+\mathrm{vaky}) \\
& \text { past }+ \text { mi }+ \text { intend fut }+ \text { man }+ \text { read } \\
& \text { I intended to read that book }
\end{aligned}
$$


b. nokasaiko (no+kasa+ina+ko) hovakina (ho+vaky+ina) io boky io past + intend + ina +1 s.poss fut + read + ina that book that

I intended to read that book

(??) That book was intended by me to be read

Even the forced passive translation of (26b) above is not accurate, since in English the Agent of be read is not bound. Note too that in both morphologies the verb read is selected in the future, governed by the verb 'intend' (in the past).

Coordinate structures, as in (27), from Malagasy novels (Keenan 1995) show possessor Agent control (with new verb types), unexpected if it is a non-active agent.

(27) a. araka izao [[ahitana- $\varnothing_{\mathrm{i}} \quad$ sy ahafantara-nareo $\left.{ }_{\mathrm{i}}\right] \quad$ ahy] izao according this [[[see+ana and know+ana]+2.poss.pl] 1s.acc] this according to this which you see and understand (of) me

b. ataoko fa $\left[\right.$ voa + jery $-\varnothing_{\mathrm{i}}$ sy voa + dinikao $\left._{\mathrm{i}}\right]$ tsara ireo sary teo I+think that [[voa+see and voa examine+2s.poss] good those picture there] I think that you have seen and examined well those pictures there

3.3.5 Selection Both free and bound verbs are selected by modal verbs. mahazo 'can' and mahay 'able' select free verbs, their roots azo and hay select bound ones. Replacing free by bound verbs in (28a) and (29a) is ungrammatical.

(28) a. mahazo manao (man+tao(v)) izany aho

permitted man+do that I

I can do that

b. tsy azoko (azo + ko) atao izany

not $\quad$ can +1 s.poss $\mathbf{a}+$ do that

I can't do that

(29) a. mahay manoratra (man+soratra) amin'io penina io aho

can write man+write with'that pen that 1s. $\delta$

I am able to write with that pen

b. tsy haiko (hay + ko) anoratana (man+soratra+ana) io penina io

not able+1s.poss man+write+ana that pen that

I can't write with that pen

In sum, treating ina/a forms as European passives breeds confusion. Outside of IndoEuropean (Haspelmath 1990) aux+participle passives are little attested.

\subsection{Further predicate building functions in Malagasy}


Voice alternations of the sort we have exhibited are central to Malagasy in a way in which the active/passive alternation in English is not. All verbs have at least two voice forms (one the -ana suffix form in (1d), discussed below) and some have as many as nine (not counting semantically significant affixing, as with reciprocals and causatives). So here we display, less thoroughly than above, a few further voicing affixes and then treat the non-primary -ana forms which have been problematic for mainstream approaches.

3.4.1 Zero prefix free forms There are about 20 common roots, all vowel initial, which form the present and imperative with initial $m$. They also form -ana suffix forms (below) regularly. So we treat them as having a free zero prefix as they lack an overt one. Examples are -ila 'need', -ino 'believe', -indrana 'borrow', -anana 'possess' and -iditra 'enter'. The first four have -ina forms and thus form theta equivalent Ss.
(30) a. m+ø+íla (míla) azy aho
Pres $+0+$ need 3.acc 1 s. $\delta$
I need her
b. Ila+ina+ko (iláiko) izy need+ina+1s.poss $3 . \delta$
I need her

3.4.2 Roots Malagasy has a large number of bound roots which function as P2s without affixation. They take a poss Agent and a $\delta$ Theme. They usually form free verbs with man or mi and are often in the domain of ina. The ina form is dynamic, the root form more static (Paul 1999). But the lexical root does directly suffix a possessor Agent.

\begin{tabular}{llll} 
Root $\mathrm{r}$ & \multicolumn{1}{c}{ ina(r) } & man(r)/mi(r) & \\
tápaka & tapáhina & manápaka & 'cut, decide' \\
hadíno & hadinóina & manadíno & 'forget' \\
héno & henóina & mihéno & 'listen to' \\
résy & reséna & mandrésy & 'defeat' \\
ré & $* * *$ & mandré & 'hear, sense'
\end{tabular}

(32) a. Tsy mbola tapaky ny olon-dehibe izany raharahaizany not yet cut the person-big.poss that work that That matter hasn't been decided by the leaders yet

b. Notapahin'ny zaza maditra ity zana-kazo ity pst+cut+ina'the child naughty.poss this offspring-tree this This young seedling was cut off by the naughty child

c. Tsy mbola nanapa-kevitra (nanapaka hevitra) ny fanjakana... not yet pst+man+cut-thought the government The government still hasn't decided...

Root predicates, such as adjectives, do not mark past tense and only mark future with full forms even when vowel initial: 

(33) a. Adala izy
crazy he
b. *Nadala / *No adala izy
c. Ho adala izy
Past+crazy / Past crazy he
Fut crazy he
He is/was crazy
He was crazy
He will be crazy

In (32a) the use of past tense no would be ungrammatical, whereas it is natural with the ina form of the verb in (32b). And while there are semantic differences between the stative and dynamic bound forms they appear to form theta equivalent pairs. However, as a reader suggests, possibly a finer analysis of theta roles would distinguish Cause in the bare root case from Agent in the suffix one, losing theta equivalence. Similarly then the roots and their corresponding man or mi forms would not be theta equivalent. The free and bound forms in the imperative would remain theta equivalent:
(34) a. Reseo
izy ireo
Defeat+ina+imp $3 . \delta$ dem.pl
Defeat them!
b. Mandresea azy ireo! man+defeat+imp3.acc dem.pl Defeat them!

3.4.3 Free Roots? There are only three free roots in common usage: tonga 'arrive', avy 'come', and lasa 'gone (past tense)'. They do not take the initial $m$ characteristic of free forms in the present and they do not directly form -ana forms (below).
(35) a. Tonga izy
b. Avy ny orana
arrive he come the rain
c. Lasa izy gone he He is arriving/has arrived It is raining / rained
He is has left

So free roots are few but bound ones many, at least 25 (possibly many more). Equating bound forms with passives, these data suggest that passive is the more basic form.

3.4.4 voa is a bound PBF which prefixes voa to roots. Its domain overlaps significantly with that of ina: voatolotra/tolorana 'offered', voafitaka, fitahina 'deceived', voavonjy, vonjena 'saved'. But voa verbs focus on the final state of an activity, ina on the process. Voa verbs lack imperatives, and like bare roots are not marked for past tense. They select a $\mathrm{DP}_{\text {poss }}$ Agent naturally, but it is often absent in discourse.

(36) a. Voa+kapoka (voakapoka) ilay alika voa+ beat that (aforementioned) dog That dog was beaten
b. no+laza+ina+ko (nolazaiko) izany past+say+ina+1s.poss that I said that
c. voa+laza+ko (voalazako) izany $\mathbf{V o a}+$ say+1s.poss that I said that

There are yet further affixes which apply primarily to roots, but in the interests of space we just list them: the prefix tafa- and the no longer productive infix -in-/-on-, as in tafatolotra and tonolotra, create bound verbs, whereas $(m) a-,(m) a n a-$ and the very productive $(\mathrm{m}) a h a$ - are free. $(\mathrm{m}) a h a$ - has abilitative and indirect causative meanings (Phillips 2000). We turn now to the highly productive suffix -ana in (1d). 
3.4.5 ana suffixes -ana (rarely -anana) to all affixed free verbs ${ }^{13}$, but not to bound ones or to roots. It creates bound verbs. ana applies to free verbs built from semantically rich secondary affixes, such as ( $m$ )if- 'Reciprocal'(Keenan \& Razafimamonjy 2004) and (m)amp- 'Causative' (Randriamasimanana 1986; Andrianierenana 1996), which build free verbs from already affixed free verbs less initial $m$.

(37) a. [n+man+enjika (nanenjika) ny jiolahy t+amin'ny fiara] Rabe

man past+man+chase the thief past+with'the car Rabe Rabe chased the thief by means of the car

b. [n+[man+enjika]+ana+Rabe (nanenjehan-dRabe) ny jiolahy] ny fiara ana past+[[man+chase $]+$ ana $]+$ Rabe.poss the thief the car Rabe chased the thief in/with/...the car

(38) a. man+taov (manao) ny farafara ho an-dRasoa Rabe man+do the bed for-Rasoa Rabe Rabe is building the house for Rasoa

b. $\varnothing+[[m a n+$ taov $]+$ ana $]+$ Rabe (anaovan-dRabe) ny farafara Rasoa pres+man+make+ana+Rabe.poss the bed Rasoa Rabe is making the bed for / because of Rasoa

ana verbs form present, past, future and imperatives as do bound verbs in general. The $\mathrm{DP}_{\delta}$ of an ana verb usually bears an oblique theta role - Benefactive, Instrument, Cause, Location, Time, Manner, Price,..., not selected by the free verb ana applies to (see K\&P, and Paul 1999). The Theta role of the $\mathrm{DP}_{\delta}$ of an ana verb is not uniquely determined. In (38a) the Prep ho an' forces a Benefactive role for Rasoa but in (38b) the $\mathrm{DP}_{\delta}$ could be any appropriate oblique. Usually few are appropriate, (Instruments are not Benefactees) but in this case Cause is possible (Maybe Rasoa nagged Rabe so much he gave in). (39a) illustrates the application of ana to an Agent/Theme P2. (39b) is the general statement.

$$
\begin{aligned}
& \text { ana } \\
& \text { (39) a. (v, } \left.\mathrm{S}\left[\mathrm{DP}_{\text {acc:TH}}, \mathrm{DP}_{\delta: \mathrm{AG}}\right]\right) \rightarrow\left(\mathrm{v}+\mathrm{ana}, \mathrm{S}\left[\mathrm{DP} \mathrm{poss:AG}_{\mathrm{AG}}, \mathrm{DP}_{\text {acc:TH}}, \mathrm{DP}_{\delta}\right]\right) \\
& \text { b. }\left(\mathrm{v}, \mathrm{S}\left[\mathrm{DP}_{\mathrm{cl}: \theta 1}, \ldots, \mathrm{DP}_{\delta: \theta n}\right]\right) \rightarrow\left(\mathrm{v}+\mathrm{ana}, \mathrm{S}\left[\mathrm{DP}_{\mathrm{poss}: \theta n}, \mathrm{DP}_{\mathrm{cl}: \theta 1}, \ldots, \mathrm{DP}_{\mathrm{cn}-1: \theta \mathrm{n}-1}, \mathrm{DP}_{\delta}\right]\right)
\end{aligned}
$$

Note that $\mathrm{c} 1 \neq$ poss, otherwise the derived ana form has two $\mathrm{DP}_{\text {poss }}$, violating Axiom 3a. Also $\mathrm{DP}_{\delta}$ there is assigned no theta role, which is inferred from context, usually different from the selected theta roles. So an ana sentence is not quite theta equivalent to a free form with an overt PP. (40) illustrates some possible interpretations of ana forms.
(40) miénjika
manénjika
runs away
ienjéhana
anenjéhana
circumstance of fleeing
mifanénjika
chases
ifanenjéhana
circ. of chasing
mampifanénjika
chase each other
ampifanenjéhana circ. of causing to chase e.o. 
(41) Inona no nifanenjehan-dRabe sy Ravao omaly? what Foc past+Rec+man+chase+ana -Rabe.poss and Ravao yesterday Why were Rabe and Rasoa chasing each other yesterday?

In isolation inona is just What?, but given the ana verb it must be questioning some circumstance of the action, and Cause/Reason is plausible here.

We derive ana verbs by extending the domain of Merge to concatenate PPs and adverbials with Pn's to form Pn's (independently needed). PPs and adverbials denote predicate modifiers - functions $\mathrm{H}$ mapping Pn denotations $\mathrm{P}$ to Pn denotations $\mathrm{H}(\mathrm{P})$. Usually $\mathrm{H}$ is restricting: $\mathrm{H}(\mathrm{P}) \leq \mathrm{P}$, meaning that for all n-tuples of entities $\mathrm{x}$, if $\mathrm{H}(\mathrm{P})(\mathrm{x})=$ True then $\mathrm{P}(\mathrm{x})=$ True. For Max is restricting in (42a), so (42a) entails (43b).

(42)a. Sue opened the box for Max

b. Sue opened the box
$(($ for Max $)($ open $))($ the box $)($ Sue $)$ open(the box)(Sue)

So Prepositions denote functions $\mathbf{p}$ mapping entities to restricting functions $\mathrm{H}$, and ana verbs quantify over such $\mathbf{p}$ as in (43), the ana form of a transitive verb. (39b) is derived as in (44) and compositionally interpreted as in (45), tense omitted.

$$
\llbracket \operatorname{ANA}(v) \rrbracket(x)(y)(z)=\text { True iff } \exists \mathbf{p}(\mathbf{p}(\mathrm{z})(\llbracket v \rrbracket)(y)(x)=\text { True } \wedge \mathbf{p} \neq \theta 1, \theta 2)^{14}
$$

$$
\begin{aligned}
& \text { S } \\
& \mathrm{S}\left[\mathrm{DP}_{\delta}\right] \\
& \mathrm{S}\left[\mathrm{DP}_{\mathrm{acc}}, \mathrm{DP}_{\delta}\right] \\
& \mathrm{S}\left[\mathrm{DP}_{\mathrm{poss}}, \mathrm{DP}_{\mathrm{acc}}, \mathrm{DP}_{\delta}\right] \\
& \mathrm{S}\left[\mathrm{DP}_{\mathrm{acc}}, \mathrm{DP}_{\delta}\right] \\
& \mathrm{RT}_{\{\mathrm{AG}, \mathrm{TH}\}} \\
& \text { aN taov ana Rabe ny farafara Rasoa } \\
& \begin{array}{llllll}
\text { AN } & \text { TAOV } & \text { ANA } & \mathrm{r} & \mathrm{f} & \mathrm{s}
\end{array}
\end{aligned}
$$

ANA(AN(TAOV))

(ANA(AN(TAOV)))(r)

(ANA(AN(TAOV)))(r)(f)

(ANA(AN(TAOV)))(r)(f)(s) 
Crucially the semantic interpretation of the ana verb uses that of the man verb it takes as argument. And since $\mathbf{p}(\mathrm{x})$ is restricting, a nuclear ana $\mathrm{S}$ like (38a) entails the man (46) which lacks a PP corresponding to the $\mathrm{DP}_{\delta}$ argument of the ana form.

(46) man+taov (manao) ny farafara Rabe

man+make the bed Rabe

Rabe is building the bed

The last line of (45) is True iff for some $\mathbf{p}, \mathbf{p}(\mathrm{s})(\mathrm{AN}(\mathrm{TAOV})(\mathrm{t}))(\mathrm{r})=$ True. And since $\mathbf{p}(\mathrm{s})$ is restricting, the last line entails $\mathrm{AN}(\mathrm{TAOV})(\mathrm{b})(\mathrm{r})$, the interpretation of Rabe is making the bed. Thus our semantics for ana Ss entails that Rabe is Agent of make and the bed is Theme. Consider now the predictions of theta equivalence between an ana $\mathrm{S}$ and a corresponding man one with an overt oblique, as in $(38 a, b)$.

On our semantics (38a) entails (38b), but the converse fails. (38b) is true in a model in which Rasoa's nagging prompted Rabe to build a bed for sale not for her. Our analysis also shows that the possessor complement Rabe in (38b), has the same theta role, Agent, as the P1 argument in (38a), and ny farafara 'the bed' is Theme in both Ss. But while Rasoa is a Benefactive in (38a), forced by the choice of Prep ho an- 'for', Rasoa is not assigned a theta role in (38b). So (38a,b) are not fully theta (or logically) equivalent. Our semantics just quantifies over functions from entities to restricting functions, different theta roles for Rasoa correspond to different choices of function. Thus on our analysis an ana $\mathrm{S}$ is vague, not ambiguous, regarding the theta role of its $\mathrm{DP}_{\delta}$. We just know that it bears some non-Agent, non-Theme relation to the predicate denotation. The case is similar to the bridge where the spies meet, which is unspecific but not ambiguous according as the spies meet under, on, or next to the bridge.

The syntax and semantics of ana verbs has proven the most challenging for all approaches to voice affixes in Malagasy (though causative mamp-, also valency increasing, is not without problems). We will see them in best relief in relative clauses, 4 below, so here let us just summarize what we are committed to so far:

(47) a. Semantically an ana-P1 maps $\mathrm{DP}_{\delta}$ denotations to truth values, assigning them a novel oblique relation: Place, Time, Means/Instrument, Cause/Reason, Manner, Benefactee, Location, Purpose, Price, or Point of view [RR:112-3], and

b. Syntactically, oblique relations are denoted by Prepositions or locative deictics, but like all $\mathrm{P} 1 \mathrm{~s}$, ana-P1s select a $\mathrm{DP}_{\delta}$ not a $\mathrm{PP}$ or a locative as last argument.

(47) prompts, I claim, a surface pragmatic principle, which helps avoid excessive vagueness when forced to assign a theta role to an overt DP.

Oblique Choice Constraint (OCC)

Given a P0 consisting of an ana-P1 + an overt $\mathrm{DP}_{\delta} \mathrm{d}$

interpret d as Means, Benefactee, or Location

The OCC is not a semantic principle. ana-P1s quantify over relations other than Means, 
Benefactee, and Location. They are used in (48c,d) whose ana-P1s lack overt $\mathrm{DP}_{\delta} \mathrm{s}$. Only (48b) with an overt $\mathrm{DP}_{\delta}$ is uninterpretable, as happiness isn't a location, benefactee, or instrument/means. We return to these cases after discussing relative clauses.

(48) a. miarahaba anao amin-kafaliana lehibe izahay $\mathbf{m i}+$ greet 2s.acc with-happiness big 1.excl We greet you with great happiness

b. \#iarahaba+ana+nay (iarahabanay) anao ny hafaliana lehibe greet+ana+1.excl.poss $\quad$ 2s.acc the happiness big

c. amin-kafaliana lehibe no iarahaba+ana+nay (iarahabanay) anao with-happiness big Foc greet+ana+1.excl.poss 2s.acc It is with great happiness that we greet you

d. ny hafaliana lehibe (izay) iarahaba+ana+nay anao the happiness big (which) greet+ana+1.excl.poss 2s.acc the great happiness with which we greet you

\section{Relative Clauses (RCs) and "Subjects only"}

The derivation and interpretation of RCs in Malagasy has been assumed modeled on the wh-movement approach used for English and other languages.

(49) a. manasa (man+sasa) lamba amin'io savony io ny tovoloahy washes (man+wash) clothes with'that soap that the young.man

b. (ny) tovolahy (izay) manasa lamba amin'io savony io (the) young.man (that) washes clothes with'that soap that

c. (ny) tovolahy $\quad\left[\mathrm{wh}_{\mathrm{i}}\left[\mathrm{p}_{\mathrm{P}}\left[\mathrm{p}_{\mathrm{P} 1}\right.\right.\right.$ manasa lamba amin'io savony io $\left.\left.]\left[\mathrm{t}_{\mathrm{i}}\right]\right]\right]$. (the) young.man who washes clothes with'that soap that $t$

d. $\mathrm{b} \in \llbracket\left(w_{\mathrm{i}}\right) \phi \rrbracket(\mathrm{B})$ iff $\mathrm{b} \in \mathrm{B} \& \llbracket \phi \rrbracket\left[\mathrm{t}_{\mathrm{i}} / \mathrm{b}\right]=$ True

(40d) says that for $\phi$ a P0 of any complexity, $\llbracket\left(w h_{i}\right) \phi \rrbracket$ maps a set B - in (40c) the set of young men - to the set of those $b$ in $B$ that $\phi$ is true of when $t_{i} i$ set to denote $b$. The semantics in (40d) is compositional and extensionally correct. That $\phi$ be arbitrary is important. For then if the position of $\mathrm{t}_{\mathrm{i}}$ in $\phi$ violates Subjacency, Coordinate Structure, etc. $\left(w h_{i}\right) \phi$ is still interpreted, and ungrammaticality is due to syntactic constraints.

(50) a. *ny lamba (izay $\left.{ }_{\mathrm{i}}\right)$ manasa $\quad \mathrm{t}_{\mathrm{i}}$ amin'io savony io ny tovolahy theclothes (that) man+wash t with'that soap that the young.man

a'. ny lamba ( izay $_{\mathrm{i}}$ ) sasan'ny tovolahy amin'io savony io $\mathrm{t}_{\mathrm{i}}$ the clothes (that) wash+ina'the young.man.poss with that soap that 
b. *ny savony (izay ${ }_{\mathrm{i}}$ ) manasa lamba (amina) $\mathrm{t}_{\mathrm{i}}$ ny tovolahy
the soap (that) man+wash clothes (with) $\mathrm{t}$ the young.man

b’. ny savony (izay $)_{\mathrm{i}}$ ) anasan'ny tovolahy lamba $\mathrm{t}_{\mathrm{i}}$ the soap (that) [man+wash]+ana'the young.man.poss clothes the soap that the young man washed clothes with

$$
\begin{array}{ll}
\text { b’. * *ny savony (izay) sasan’ny tovolahy } & \text { lamba (amina) } t_{\mathrm{i}} \\
\text { the soap (that) wash+ina'the young.man.poss } & \text { clothes (with) }
\end{array}
$$

The paradigm in (50) is well supported in the literature. Keenan 1972 and GHT 1992 used this approach to claim "Only subjects relativize", later "Only subjects extract". But this approach misses a striking generalization: RCs in Malagasy are just P1s, not arbitrary Ss with a bound variable. In all the starred cases the verb does not have the correct morphology for the trace to be its $\mathrm{DP}_{\delta}$. Thus, writing $\cap$ for set intersection,

$$
\begin{aligned}
& \text { The Malagasy Relative Clause Generalization: RC }=\mathbf{P} 1 \\
& \text { Syntax: } \quad \text { Malagasy headed RCs have the form: Noun + P1 } \\
& \text { Semantics: } \\
& \llbracket \text { Noun }+\mathrm{P} 1 \rrbracket=\llbracket \text { Noun } \rrbracket \cap\{\mathrm{x} \mid \llbracket \mathrm{P} 1 \rrbracket(\mathrm{x})=\text { True }\}^{15}
\end{aligned}
$$

$\mathbf{R C}=\mathbf{P 1}$ is also pleasingly Minimalist. To form and interpret RCs we just use P1s we have already formed and interpreted. We don't introduce novel elements - variable binding operators or bound variables (traces) in the computation ${ }^{16}$. We have a voice system that already does the job. And we don't need to constrain the positions we can extract from, as we are not "extracting". But the content of "Subjects Only" holds.

This perspective is actually not so surprising. Why would a grammar provide seven morphologically different forms of offer to say I offered rice to the guests on this dish? Surely this elaborate morphological apparatus will be used for something in the syntax, and it is. It codes what we can relativize (question, cleft, ...), functionally comparable to the relative pronoun systems of Latin or Russian. (Similarly a rich noun class system, as in Bantu, guarantees the existence of an agreement system, Corbett 1991:105).

Summary We have, as promised, formally characterized voice and relativization in Malagasy without recourse to movement. But is our analysis descriptively adequate? Here are a few natural semantic and syntactic challenges to our proposals.

\subsection{Three semantic challenges to $\mathrm{RC}=\mathrm{P1}$}

First, our semantics captures selection restrictions in truth conditions even though the head $\mathrm{N}$ of a $\mathrm{RC}$ never occurs in the $\mathrm{DP}_{\delta}$ position. \#Nanenjika ny alika ny trano 'The house chased the dog' is bizarre as it implies that houses can autonomously move and in fact they can't. When we suspend real world beliefs, as in cartoon contexts, the sentence is fine. And our RCs are understood comparably. An object in our denotation for the RC trano nanenjika ny alika 'house (that) chased the dog' is a house which chased 
something, so again autonomous movement of houses is implied.

Second, a reader queries whether we can interpret reflexives correctly in P0s built from bound verbs since it would appear that the anaphor asymmetrically c-commands its antecedent. And it does. One of the main empirical points of K\&S is to show how binding among arguments works independently of how the AA (Anaphor-Antecedent) relation is coded. A full discussion of binding in Malagasy would be a paper in its own right. So here we just adapt $\mathrm{K} \& \mathrm{~S}$ to show how the c-command issue disappears.

Define a function self which maps binary relations $\mathrm{R}$ to the set of objects $\mathrm{b}$ such that the pair (b,b) $\in \mathrm{R}$. Now let $r$ be a $\mathrm{RT}_{\{\mathrm{AG}, \mathrm{TH}\}}$ in $\operatorname{Dom}(\mathbf{m a n}) \cap \operatorname{Dom}(\mathbf{i n a})$. Then man(r) and ina(r) are both two place functions taking individuals as arguments. We extend their domains so that man(r) takes self as argument yielding the one place function of individuals given in (52a). Ina(r) still takes individuals b as arguments to yield functions taking self type things as arguments, as in (52b) ${ }^{17}$ :

(52) a. $(\operatorname{man}(r)($ self $))(b)=\operatorname{man}(r)(b)(b) \quad$ and $\quad b .($ ina $(r)(b))($ self $)=$ ina(r)(b)(b)

That man(r)(b)(b) and ina(r)(b)(b) are the same truth value follows from Proposition 2. One sees easily that $(52 \mathrm{a}, \mathrm{b})$ can provide compositional interpretations. The tough case in terms of c-command is:

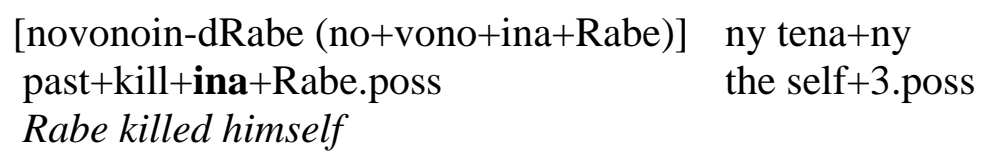

Ignoring tense and treating ny tenany as denoting self the interpretation of (53) follows the formula in (52b): ((ina(kill))(Rabe))(self).

Third, there remains a learnability issue concerning the interpretation of ana-P1s in RCs. Semantically they select an oblique relation on their argument. But the OCC in practice rules out overt arguments interpreted as Manner, Cause/Reason, etc., only allowing Means, Benefactee, and Location. So what language exposure prompts the learner to assign the Manner meaning to (54a) and the Cause/Reason meaning to (54b) given that DPs with those meanings don't occur as overt arguments of the ana-P1s?

(54) a. ny hafaliana lehibe niarahabanay ( $n+m i+a r a h a b a+a n a+n a y)$ anao the happiness big past+mi+greet+ana+1.excl.poss 2s.acc the great happiness with which we greeted you

b. ny antony nanaovako $(\mathrm{n}+\mathrm{man}+\mathrm{taov}+\mathrm{ana}+\mathrm{ko}) \quad$ izany the reason past + man + do+ana+1s.poss that the reason $I$ did that

And relatedly, what drives the OCC? Specifically, why select Means, Benefactee and Location? Selecting just Manner and Cause/Reason would also reduce vagueness. 
Two questions, two responses: First, there are other contexts that select P1s and in which ana-P1s occur with an explicit indicator of their oblique relation. Second, there are independent constraints on P1 arguments that disfavor certain oblique interpretations.

One other P1 selecting context is given by the very widely used Focus construction, illustrated in (55) and studied in Paul 2001.

(55)a. Rabe no [nanenjika ny jiolahy tamin'ny fiara $]_{\mathrm{P} 1}$ Rabe Foc pst+man+chase the thief pst+Means'the car It was Rabe who chased the thief using the car

b. Ny jiolahy no [nenjehin-dRabe tamin'ny fiara $]_{\mathrm{P} 1}$ the thief Foc pst+chase+ina-Rabe.poss pst+Means'the car It was the thief that Rabe chased using the car

c. (Tamin') ny fiara no [nanenjehan-dRabe ny jiolahy $]_{\mathrm{P} 1}$ (pst+Means') the car Foc pst+manchase+ana-Rabe.poss the thief It was by means of the car that Rabe chased the thief

d. Tamin'ny fahazotoam-be no [nanenjehan-dRabe ny jiolahy $]_{\mathrm{P} 1}$ Pst+with'the zeal- big Foc pst_man+chase+ana-Rabe.poss the thief It was with great zeal that Rabe chased the thief

In all the examples the post no constituent is a P1 whose argument is semantically bound by the focus (pre-no) constituent which makes the oblique relation explicit. In the first three the pre-no constituent could occur as an overt post-P1 argument (less the Prep in (55c)). But this is not possible in (55d), where the Prep is obligatory. The post-no P1 in (55d) is identical to that in (55c). Here are some other examples with other Preps.

(56) a. Momba ny fifidianana no niresahanay (n+mi+resaka+ana+nay) about the elections Foc pst $+\mathbf{m i}+$ conversation+ana+1.excl.poss It was about the elections that we were speaking

b. Noho ny andro alina no odiako ( $\varnothing+$ ody+ana+ko) haingana cause the day night Foc 0+go.home+ana+1s.poss quickly It is because it is dark that I'm going home quickly

c. Mandritra taona iray no hitoeranay ( $\mathrm{h}+\mathrm{mi}+$ toetra+ana+nay) any Betafo during year one Foc fut+mi+reside+ana+1.excl.poss loc Betafo We will reside in Betafo for one year

Also noteworthy here is that focusing does not require definiteness (Paul 2001), whence the naturaleness of forming $\mathrm{DP}_{\delta}$ questions from the cleft structure (Sabel 2003). 

(57) a. vato no hanaovako $(\mathrm{h}+\mathrm{man}+\mathrm{taov}+\mathrm{ana}+\mathrm{ko})$ ny trano+ko stones Foc fut + man + do + ana +1 s.poss the house +1 s.poss
It is with stones that I will build my house

(Malzac:71)
a'. Inona no hanaova + nao
ny trano+nao?
what Foc fut+man+do+ana+2s.poss the house+2s.poss
What will you build your house from?
b. lobaka no sasan-dRasoa (sasa+ina+Rasoa) (fa tsy pataloha) shirts Foc wash+ina+Rasoa.poss but not pants
It is shirts that Rasoa is washing (not pants)

In general then what follows the focus particle no in a cleft is a $\mathrm{P}^{18}$. And this is a basic paradigm which leads language learners to interpret ana-P1s as P1s which impose an oblique interpretation, even when they don't take a corresponding overt DP sister. And once we can interpret ana-P1s as P1s we can use them in RCs:

(58) a. ny vehivavy anaovako (man+taov+ana+ko) trano the woman man+do+ana1s.poss house the woman for whom I am building a house
b. io alina nodiako $(\mathrm{n}+\varnothing+\mathrm{ody}+\mathrm{ana}+\mathrm{ko}) \quad$ haingana io that night past $+0+$ go.home + ana +1 s.poss quickly that that evening when I went home quickly
c. ny vato hanaovako $(\mathrm{h}+\mathrm{man}+\mathrm{taov}+\mathrm{ana}+\mathrm{ko})$ trano the stone fut+man+do+ana+1s.poss house the stone from which I will make my house

Secondly, why does the OCC selects Means, Benefactive and Locative obliques as the unmarked interpretations for DP arguments of ana-P1s? This is, I feel, due to an independent constraint on P1 arguments. Alas I don't know precisely what the constraint is, but it is tied to the well recognized "definiteness" requirement on P1 arguments in Malagasy (Tagalog, ...). Contrast:

(59) a. manenjika (ny) voalavo (*ny) akoho

chases (the) rat the chicken

The chicken is chasing rats, a rat, the rat(s)

b. misy akoho manenjika voalavo

exist chicken chases rat

There is a chicken / (some) chickens which is / are chasing (some) rats

The Theme DP in (59a) may be a bare $\mathrm{N}$ in which case it has the expected indefinite interpretation. (Number is not marked on Ns). But the P1 argument akoho 'chicken' must have a definite Det. Simply omitting its ny 'the' is roundly rejected by everyone. 
The intended sense would be expressed as an existential, as in (59b). This basic paradigm is well known. But I think it extends a little further and deeper.

One component of definiteness is referent identifiability. And instruments (shovels, knives, needles), Benefactees (human beings), and Locatives (houses, villages, rivers) are physical objects and thus visually identifiable. But the other oblique relations mentioned in (47) - Times, Causes, Manners, Purposes, Points of View, Prices are not visually identifiable. So the OCC restriction makes sense in terms of referent identifiability, rendering it less ad hoc. Perhaps this perspective can be extended to "classifier Ns" such as antony 'reason', etc. in (60):

(60) ny antony / fotoana / fomba nandehanany (n+man+leha+ana+ny)

the reason / time/ manner pst+man+go+ana+3.poss

the reason / time he went; the manner in which he went

Such Ns denote oblique properties the argument of an ana-P1 might bear and the whole DP denotes whatever has that property. As soon as we hear (in Malagasy) a DP that begins 'the reason that...', 'the time that...' we know that there will be a subordinate clause verb in ana form. The cases are reminiscent of ones from Schachter 1973 discussed in Bhatt 2002 in which the RC must be present to identify the head N:

(61) a. the clever way (*in which he solved the problem) impressed me

b. Nahagaga ahy ny fomba (*nanaovany (n+man+taov+ana+ny) ny trano+ny) surprised 1s.acc the manner pst+man+do+ana+3.poss the house+his The manner [*in which he built his house] surprised me

\subsection{Two syntactic challenges to $\mathrm{RC}=\mathrm{P1}$}

Second, there are at least two common RC types that appear not to fit our format. One is possessor RCs, as in the student whose cat I fed. In fact Malagasy can relativize a variety of possessors easily, due to its ability to form P1s whose DP sister binds a possessor position within the P1. K\&R [Keenan and Ralalaoherivony 2000] provide extensive documentation. An illustrative example is (62), built from the P1 in (63b).

(62) ny mpianatra [hadinoko anarana $]_{\mathrm{P} 1}$

the student forget +1 s.poss name

the student whose name I forget

(63)a. [Hadinoko $]_{\mathrm{P} 1}$ [ny anaran'ny mpianatra] forget +1 s.poss the name'the student.poss

I forget the name of the student

b. [Hadinoko anarana $]_{\mathrm{P} 1}$ [ny mpianatra]

forget +1 s.poss name the student

"The student is name forgotten by me" 
c. [manadino ny anaran'ny mpianatra $]_{\mathrm{P} 1}$ aho

man+forget the name'the student.poss 1s. $\delta$

I forget the name of the student

Hadino is a bound root; the free form is manadino, illustrated in (63c). It is tempting, with K\&R, to think that (62b) is derived by "DP raising” (which includes possessor raising as a special case). But this approach does not clearly guarantee that what is left after DP Raising is a P1. But they are: interrogative ve placement is correctly predicted, the following DP is in $\delta$ case, and they coordinate with other clear P1s:

(64)a. [Be sandry sady mihetraketraka] Rabe big arms and $\mathbf{m i}+$ look+for+trouble Rabe Rabe has big arms and looks for trouble

b. [Very hevitra ka miherikerika fotsiny] Ranaivo lost thought and+so mi+look+around only Ranaivo Ranaivo is confused and so just looks around

c. [Miasa loha sady mifoka loatra] i Soa works head and $\mathbf{m i}+$ smoke too+much art Soa Soa is preoccupied and smokes too much

If the left conjuncts are P1s we can coordinate them with the P1s on the right. But how can we derive (65c) for example if miasa loha is only created in contexts like (65b)?
(65) a. ??Miasa ny lohan'i Soa
"Soa's head is working"
work the head'art Soa.poss
b. Miasa loha i Soa
work head art Soa
"Soa is preoccupied"
c. Miasa loha ve i Soa?
“Is Soa preoccupied?”

And if we derived (65c) from the polar question based on (65a) the question particle ve would immediately follow Miasa, ungrammatical in (65c). Without answering this query, it is constructive to consider how P1s are formed rather than how DPs are moved. For example, the P1s in (63b) and (64a,b,c) require an argument satisfying a requirement internal to an $\mathrm{N}$ they are built from. Even more surprising cases cited in K\&R are:

(66) a.Maro [ny raharaha sahaniko (sahana+ina+ko)] many the tasks I+face confront+ina+1s.poss The tasks I am confronting are numerous

b. [Maro raharaha sahanina $]_{\mathrm{P} 1}$ aho many tasks confront+ina 1 s. $\delta$ I have many things to do 
(67) a. Fohy [ny andro niveloman-dRabe ( $n+i+v e l o m+a n a+R a b e)]$ short the day past+mi+live+ana+Rabe.poss The days during which Rabe lived were few

b. [Fohy andro nivelomana $]_{\mathrm{P} 1}$ Rabe short day lived+ana Rabe Rabe had a short life

Deriving (66b) and (67b) by DP movement violates standard constraints since it is movement from a relative clause. Important here is that the bracketed portions of (66b) and (67b) satisfy our P1 tests, including coordination above. An even more striking case of P1s formed with NP fragments is (68b). (68c) illustrates the use of the P1 as an RC.

(68)a. Be [ny asa manahirana ahy]

"The work which bothers me is extensive" much the work man+bother 1.acc

b. [Be asa manahirana] aho much work bothers 1 s. $\delta$

"I (have) much bothersome work"

c. ny [mpampianatra [be asa manahirana]]

the teachers (who) (have) much bothersome work

So Malagasy has a variety of ways of forming P1s who DP sisters bind an argument properly within the P1. Still in simple cases stage-level adjectives do not form P1s with possessor heads freeing the posssessor to be the argument of the derived predicate. Compare the natural (69b) with the unacceptable (70b).

(69) a. Fotsy [ny nifin-dRabe] white the teeth-Rabe.poss

Rabe's teeth are white

(70)a. Tezitra [ny mpiasan-dRabe] angry the workers-Rabe.poss Rabe's workers are angry b. [Fotsy nify] Rabe white teeth Rabe Rabe is white toothed

b. *?[Tezi-mpiasa] Rabe angry-worker Rabe *?Rabe is angry workered

This observation supports a P1 derivational view - it is a constraint on P1 interpretations, not on which DPs can raise. Thus (71a) below is natural, (71b) much less so.

(71)a. ny tovolahy fotsy nify the young.man white teeth the white toothed young man b. *ny tale tezi-mpiasa the boss angry worker the boss with angry workers

To express modifiers as in (71b) Malagasy can always use an overt verb of possession. The simplest choice is misy 'exist, have', as in kafe misy siramamy 'coffee with sugar' (lit: 'coffee (that) has sugar'. This option works for (71b) as well: ny tale misy mpiasa tezitra 'the boss with angry workers'. With the possession of inanimates it would be 
more natural to use manana 'possess'. So 'doctor whose house is large' = dokotera manana trano lehibe 'lit: doctor (who) has house large'.

The second potentially problematic case is relativization into complement clauses. How do we say the thief who Rabe thinks that Rasoa captured? Surprisingly Malagasy has two regular answers to this query, and both maintain $\mathbf{R C}=\mathbf{P 1}$. The first is:

(72) ny jiolahy [heverin-dRabe ho nosamborin-dRasoa] the thief think+ina+Rabe.poss Comp past+capture+ina+Rasoa.poss the thief Rabe thinks that Rasoa captured

The Ss below may help the reader to parse the bracketed P1 in (72). Note that when the matrix verb 'think' is free the complement clause, introduced in (73a) by fa, follows its $\mathrm{DP}_{\delta}$. All the Ss in (73) have the same cognitive meaning. The use of poss, $\delta$, and acc indicates the class of pronoun that would replace the full DPs. We replaced 'the thief' with the appropriate pronoun in (73b,c,d) to help readability. The Raising to Object relation between (73b) and (73c) is very productive in Malagasy, Paul and Rabaovolona 1998 cite some 50 verbs which host it).

(73) a. mihevitra Rabe fa nisambotra ny jiolahy Rasoa

mi+think Rabe. $\delta$ that past+mi+capture the thief.acc Rasoa. $\delta$ Rabe thinks that Rasoa captured the thief

b. mihevitra Rabe fa nosamborin-dRasoa izy mi+think Rabe. $\delta$ that past+capture+ina+Rasoa.poss he. $\delta$

c. [mihevitra azy ho nosamborin-dRasoa $]_{\mathrm{P} 1}$ Rabe mi+think him.acc Comp past+capture+ina+Rasoa.poss Rabe. $\delta$

d. [heverin-dRabe ho nosamborin-dRasoa $]_{\mathrm{P} 1}$ izy think+ina-Rabe.poss Comp past+capture+ina+Rasoa.poss he. $\delta$

The bracketed constituents in (73c,d) unproblematically pass our P1 tests - interrogative $v e$ occurs at the right edge, and the following DP is in $\delta$ case.

A second way of relativizing into a complement clause, adapted from [K\&R] in (74), appears less convincingly a case of RC $=\mathrm{P} 1$. Many speakers hesitate slightly at this expression, but then accept it.

(74) ny tovolahy [nolazain-dRabe fa mpangalatra]

the young.man past+say+INA+Rabe.poss Comp thief (er+steal)

the young man (that) Rabe said was a thief

If (74) is to fit our RC = P1 format the bracketed string in (74) must be a P1. It looks like the P1 in ( d) save that it uses the complementizer fa instead of ho. But that difference signals a significant difference in structure. Consider the $S$ in (75a). As both $K \& R$ and Pearson 2005 note, two placements of the question particle are acceptable: 
(75) a. Nolazain-dRabe fa mpangalatra ny tovolahy Past+say+ina+Rabe.poss that thief the young.man Rabe said that the young man was a thief

b. [Nolazain-dRabe $]_{\mathrm{P} 1}$ ve fa mpangalatra ny tovolahy? Past+say+ina+Rabe $Q$ that thief the young.man Did Rabe say that the young man was a thief?

c. [Nolazain-dRabe fa mpangalatra $]_{\mathrm{P} 1}$ ve ny tovolahy? Past+say+ina+Rabe that thief Q the young.man Was the young man said by Rabe to be a thief?

Ve placement marks the bracketed string as a P1 in (75c). And (75a) is ambiguous according as 'the young man' is the $\mathrm{DP}_{\delta}$ argument of the lower P1 or the entire P1.

5. Conclusion This concludes our discussion of the role of P1s in RC formation. We note only that in addition to RCs there are several other major structure types that build off of P1s: We have already hinted at their role in Clefts, which includes wh-questions as a special case. Another very large class of DPs can be described by the equation: $\mathbf{D P}=$ Det + P1 + (Det) illustrated in (76). See Ntelitheos (2006) for extensive discussion.

(76) Faly amin' [izao $[\mathrm{h}+\varnothing+\text { ananan'i } \quad \text { Soa tokantrano }]_{\mathrm{P} 1}$ izao $]_{\mathrm{DP}}$ izahay happy with this fut+0+have+ana'art Soa.poss household this we.ס.excl. We are happy about Soa's future having a household (getting married)

W. Austronesian languages are good at building predicates. Moving DPs is derivative.

\section{References}

Abinal, R.P. et R.P.. Malzac (1963) Dictionnaire Malgache-Français. Mission Catholique de Tananarive. Paris: Editions Maritimes et d'Outre-Mer (reprint from 1888 edition).

Aldridge, Edith. 2002. Nominalization and WH-movement in Seediq and Tagalog. Language and Linguistics 3.2 Special Issue: Nominalization in Formosan Languages, Elizabeth Zeitoun (ed). Academia Sinica. Pp. 393 - 427.

Andrianierenana, L. 1996. Morphological causatives in Malagasy. In The Structure of Malagasy M Pearson and I. Paul (eds). UCLA Occasional Papers in Linguistics 17:58 - 76 .

Bhatt, Rajesh. 2002. The raising analysis of relative clauses: evidence from adjectival modification. Natural Language Semantics 10:43 - 90.

Builles, Jean-Michel. 1984. Le Merina Thèse pour le doctorat d'état. Paris V.

Chomsky, Noam. 1957. Syntactic Structures. Mouton.

Chomsky, Noam. 1965. Aspects of the Theory of Syntax. MIT Press.

Chomsky, Noam. 1975. Reflections on Language. Pantheon.

Chomsky, Noam. 1995. The Minimalist Program. The MIT Press.

Collins, Chris. 2005. A smuggling approach to the passive in English. Syntax 8.2:81 120. 
Corbet, Greville. 1991. Gender. CUP.

Erwin, Sean. 1996. Quantity and moras: An amicable separation. In The Structure of Malagasy vol I. M. Pearson and I. Paul (eds). Dept. of Linguistics, UCLA. pp. $2-31$.

[GHT] Guilfoyle, Eithne, Henrietta Hung and Lisa Travis. 1992. Spec of IP and Spec of VP: two subjects in Austronesian languages. Natural Language and Linguistic Theory 10:375 - 414.

Haspelmath, M. 1990. The grammaticization of passive morphology. In Studies in Language 14.1:25 - 72 .

Huang, Lillian. 2002. Nominalization in Mayrinax Atayal. Language and Linguistics 3.2 Special Issue: Nominalization in Formosan Languages, Elizabeth Zeitoun (ed). Academia Sinica. pp 197 - 227.

Hyams, Nina, Dimitris Ntelitheos, and Cecile manorohanta. 2006. Acquisition of the Malagasy Voicing System: implications for the adult grammar. NLLT 24:1049 $-1092$.

Keenan, Edward L. 1972. Relative Clause Formation in Malagasy (and some related some not so related languages. The Chicago Which Hunt University of Chicago.

Keenan, Edward L. 1976. Remarkable subjects in Malagasy. In Subject and Topic C. Li (ed). Academic Press.

Keenan, Edward L. 1995. Predicate-argument structures in Malagasy. In Grammatical Relations C. Burgess, K. Dziwirek, and D. Gerdts (eds). CSLI. Stanford. pp. $171-217$

Keenan, Edward L. 1996. The semantics of determiners. In The Handbook of Contemporary Semantic Theory S. Lappin (ed). Blackwell pp. 41-53.

[K\&M 2001] Keenan, Edward L. and Cécile manorohanta. 2001. A quantitative study of voice in Malagasy. in Oceanic Linguistics vol 40:67 - 85.

[K\&M 2004] Keenan, Edward L. and Cécile manorohanta. 2004. Malagasy clause structure and language acquisition. In Proceedings of the XIth Austronesian Formal Linguistics Association. Paul Law editor. ZAS, Berlin. Pp. 178 - 203.

[K\&P] Keenan, Edward L. and Miriam Polinsky. 1998. Malagasy Morphology. In The Handbook of Morphology. A. Spencer and A. Zwicky (eds) Blackwell. pp. $563-624$.

[K\&R] Keenan, E.L. and Baholisoa Ralalaoherivony. 2000. Raising from NP in Malagasy. Linvisticae Investigationes 23:1:1 - 44.

Keenan, Edward L. and Jean-Paulin Razafimamonjy. 2004. Reciprocals in Malagasy. in Oceanic Linguistics vol. 43.1:177 - 207.

[K\&S] Keenan, E.L. and E.P. Stabler. 2003. Bare Grammar CSLI, Stanford.

Koopman, H. 2005. Malagasy imperatives. In UCLA Working Papers in Linguistics:12.

Kroeger, Paul. 1988. Verbal focus in Kimaragang. In Papers in Western Austronesian Linguistics No. 3:217 - 40. Pacific Linguistics, A-78.

Kroeger, Paul. 1993. Phrase Structure and Grammatical Relations in Tagalog. CSLI, Stanford.

Mahajan, Anoop. 1994. ACTIVE passives. WCCFL XIII. R. Aranovich et al. (Eds). pp. $286-301$.

Malzac, S.J. 1926. Grammaire malgache Paris, Société d'éditions géographiques, Maritimes et Coloniales, Paris. 
Ntelitheos, Dimitrios. 2005a. Variation in the distribution of genitive subjects in Malagasy. 35 ${ }^{\text {th }}$ Michigan Linguistic Society, Lansing.

Ntelitheos, Dimitris. 2006. The Morpho-Syntax of Nominalizations: A Case Study. PhD diss. UCLA Dept of Linguistics.

Paul, Ileana. 1996. The Malagasy genitive. In Pearson \& Paul, The Structure of Malagasy Vol I, UCLA Occasional Papers in Linguistics 17. Pp 76 - 92.

Paul, Ileana. 1999. Malagasy Clause Structure. PhD Diss. Dept. of Linguistics, McGill University

Paul, Ileana. 2001. Concealed pseudo-clefts. Lingua 111:707 - 727.

Paul, Ileana and Lucie Rabaovololona. 1998. Raising to object in Malagasy. In The Structure of Malagasy vol II I. Paul (ed). Dept. of Linguistics, UCLA. pp.50 - 65.

Pearson, Matthew. 2005. The Malagasy subject/topic as an A' element. in Natural Language and Linguistic Theory 23:381 - 457.

Phillips, V. 2000. The interaction between prefix and root: the case of maha- in Malagasy. In Formal Issues in Austronesian Linguistics I. Paul, V. Phillips, L. Travis (eds) Kluwer, Dordrecht. Pp. 85 - 105.

Prentice, D.J. 1971. The Murut Languages of Sabah Pacific Linguistics Series C - No.18. The Australian National University. Canberra, Australia.

Rabenilaina, R-B. 1993. Le verbe malgache - Etude des formes predicatives. Ambozontany: Fianarantsoa, Madagascar.

[R\&T] Rackowski, Andrea and Lisa Travis. 2000. V-Initial Languages: X or XP movement and adverbial placement. In The Syntax of Verb Initial Languages. Andrew Carnie and Eithne Guilfoyle (eds) OUP Pp. 117 - 143.

Radford, Andrew. 1997. Syntax: A Minimalist Introduction. CUP.

Rahajarizafy, Antoine. 1960. Essai sur la grammaire malgache Imprimerie Catholique, Antanimena, Tananarive

[RR] Rajemisa-Raolison, Regis. 1971. Grammaire malgache. Fianarantsoa.

Randriamasimanana, Charles. 1986. The Causatives of Malagasy Univ. of Hawaii Press.

Richards, N. 2000. Another look at Tagalog subjects. In I. Paul, V. Phillips, and L. Travis (eds). Formal Issues in Austronesian Linguistics Pp 105 - 116. Kluwer

Ross, M. 2006. The argument structure of undergoer voice clauses in Formosan and other Philippine-type languages. Presented at AFLA 13, Tsing Hua Univ. Taiwan Sabel, Joachim. 2003. Malagasy as an optional multiple wh-fronting language. In Cedric Boeckx and Kleanthes Grohman (eds). Multiple wh-Fronting 229 - 254. Benjamins. Schachter, Paul. 1973. Focus and relativization. Language 49(1):19 - 46.

Schachter, Paul. 1976. The subject in Philippine languages: topic, actor, actor-topic, or none of the above. in C. Li (ed) Subject and Topic 1976:491 - 518. Academic Press. Schachter, P. and Fe Otanes. 1972. Tagalog Reference Grammar UC Press. Wechsler, Stephen and I.Wayan Arka. 1998. Syntactic Ergativity in Balinese. In Natural Language and Linguistic Theory 16:387 - 441.

\section{Footnotes}

${ }^{1}$ In addition to Malagasy (Madagascar) we include here Tagalog (Schachter and Otanes 1972, Kroeger 1993) and Philippine languages generally, Timugon (Prentice 1971), Kimaragang Dusun (Kroeger 1988), Balinese (Wechsler and Arka 1998), Atayal (Huang, 2002) and Seediq (Aldridge 2002). 
${ }^{2}$ Erwin (1996) and Pearson (2005) show that many roots are consonant final, in distinction to their standard dictionary form (Abinal \& Malzac 1963). If a vowel is supplied via a suffix the final consonant, possibly mutated, is pronounced. With no suffix the consonant drops. For example, from the root taov- 'do' we derive atao 'does', with loss of $-v$, but imperative atovy. We are not concerned here with the morphophonology of affixation and tend to give roots in their dictionary form.

${ }^{3}$ When $\mathrm{F}$ is a two place function on $\mathrm{A}$ and $\alpha$ is an element of $\mathrm{A}$, we can define a one place function $F_{\alpha}$ from $A$ to $A$ which maps each $\beta$ in $A$ to $F(\alpha, \beta)$. Here we think of Merge as taking some pairs (man, $r$ ) as arguments, and we treat man as an abbreviation for the one place function Merge $\mathrm{man}_{\text {man }}$.

${ }^{4}$ man maps pairs (s,C) to pairs (s',C'). In our example it maps the 's' coordinate enjika to manenjika, the concatenation of man with enjika, in the tree (10b). But often the derived string is not simply concatenation with man: the initial consonant of a root may drop or mutate: $\mathbf{m a n}($ tolotra $)=$ manolotra man(halatra $)=$ mangalatra 'steals', etc. We ignore these spell out problems here. This complexity is typical of W. Austronesian. ${ }^{5}$ P0s denote elements of $\{$ True, False . Ultimately we need proper intensions, but for now extensional simplicity rules.

${ }^{6}$ In addition six man verbs, recognized as exceptional in traditional grammars, are in Dom(ina): Ex: $\operatorname{man}($ halatra $)=$ mangalatra 'steals'; ina $($ mangalatra $)=$ angalarina . ${ }^{7}$ Mostly with -( $\left.v\right) n a$ suffixes, the choice of vowel is conditioned by the root. But Rahajarizafy notes a few exceptions. We call the affixing function ina after its most common exponent.

${ }^{8}$ We intend the 20 , listable, affixes introduced by PBFs. $\Theta(p)$ is $\{\theta 1, \ldots, \theta n\}$ when the category of $\mathrm{p}$ is $\mathrm{S}\left[\mathrm{C} 1_{\mathrm{c} 1, \theta 1}, \ldots, \mathrm{Cn}_{\mathrm{cn}, \theta n}\right]$ or $\mathrm{RT}_{\{\theta 1, \ldots, \theta \mathrm{n}\}}$.

${ }^{9}$ We are not free to decide that two expressions $d$, d'are or are not isomorphic. Once the lexicon and the structure building functions are given then either there is an automorphism mapping $d$ to d' or there isn't. It is a matter of proof, not introspection. ${ }^{10}$ Mathematically we may treat a single expression as unary relation with one member. 11 suppose nuclear Ss $\Phi, \Psi$ are theta equivalent by f. Let h an arbitrary automorphism. Then in effect hofoh ${ }^{-1}$ bijectively maps the arguments of $h(\Phi)$ to those of $h(\Psi)$ preserving theta role in each case, whence $h(\Phi) \equiv_{\Theta} h(\Psi)$

${ }^{12}$ mi- verbs: mierika ny andro 'It is drizzling', mikotraka ny orana 'The rain thunders'; adjectives: ratsy/tsara/mafana ny andro 'the weather is bad/good/hot'; one free root verb: ho avy ny orana 'the rain will come'; even nouns: alina ny andro 'It is night'.

${ }^{13}$ We choose freedom not $m$ marking as definitional in the domain of ana since there are two $m$ prefixes - miha 'become' and miaraka 'do together' which occur outside tense marking and do not feed ana:

\begin{tabular}{|c|c|}
\hline $\begin{array}{l}\text { mihamangatsika aho } \\
\text { Jam getting cold }\end{array}$ & nihanangatsiaka aho \\
\hline niara-n̄angalatra & ny omby izy roa lahy \\
\hline $\begin{array}{l}\text { past }+ \text { together-past }+ \text { man }+ \text { steal } \\
\text { The two men together stole the }\end{array}$ & $\begin{array}{l}\text { the cow } 3 \text { two man } \\
\text { cow }\end{array}$ \\
\hline
\end{tabular}

${ }^{14} \mathbf{p} \neq \theta \mathrm{i}$ means $\mathbf{p}(\mathrm{z}) \llbracket \mathrm{v} \rrbracket \neq \theta \mathrm{i}(\mathrm{z}, \llbracket \mathrm{v} \rrbracket)$

${ }^{15}$ The P1 of a RC may be preceded by izay (morphologically constant) interpreted as: 
$\operatorname{IZAY}(\mathrm{P})(\mathrm{B})=\mathrm{B} \cap\{\mathrm{x} \mid \mathrm{P}(\mathrm{x})=$ True $\}$. $\mathrm{B}$ is a Noun denotation, $\mathrm{P}$ a $\mathrm{P} 1$ one. Thus RCs with or without izay are both interpret the subordinate clause as a P1. And the denotation of $\mathrm{N}+$ (izay) $+\mathrm{P} 1$ is the same whether izay is present or not (it usually is not).

16 "any structure formed by the computation ... is constituted of elements already present in the lexical items...; no new objects are added in the course of computation apart from rearrangements of lexical properties...” (Chomsky 1995:228).

${ }^{17}$ The only fact about self that we use here is that it is not a generalized quantifier which lifts a function from properties to truth values.

${ }^{18}$ There is one well known exception. Locative and temporal adjuncts can cleft in three ways, one of which leaves the post-no expression an apparent complete S. Thus It is in Betafo that Rabe resides can be rendered as (a), (b), or (c):

a. Any Betafo no [itoeran-dRabe.poss $]_{\text {ana-P1 }}$

b. Any Betafo Rabe. $\delta$ no [mitoetra $]_{\mathrm{mi}-\mathrm{P} 1}$

c. Any Betafo no [mitoetra Rabe. $\delta]_{\mathrm{P} 0}$

What follows no in (a) and (b) is a $\mathrm{P} 1$, but in (c) it is a mi verb with a $\mathrm{DP}_{\delta}$. Still, despite this one exception the post-no position in clefts selects for P1s, and all clear P1s are able to occur there. 